\title{
REMINISCENCIAS MEDITERRÁNEAS EN CERÁMICA IBÉRICA. EL EJEMPLO DEL CORRAL DE SAUS

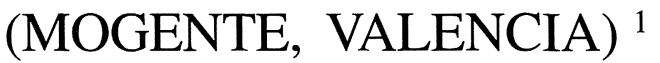

\author{
POR
}

\author{
M. ${ }^{a}$ ISABEL IZQUIERDO PERAILE \\ Departament de Prehistòria i Arqueologia. Universitat de València
}

\section{RESUMEN}

La inicial revisión y el estudio del contexto arqueológico de esta necrópolis ibérica ha evidenciado un interesante conjunto de materiales, además de identificar diversos enterramientos y sus respectivos ajuares. A través de estos datos ha sido posible acotar, de una manera aproximada, los límites cronológicos de la necrópolis. En esta ocasión, a partir de la presentación de un conjunto de cerámicas ibéricas, valoramos el conocido y complejo fenómeno de las imitaciones cerámicas.

\section{ABSTRACT}

The initial revision and archaeological context study of this Iberian necropolis have showed an interesting lot of materials, allowing us to identify different graves and their respective funerary goods. Through these facts, it has been possible to fix, approximately, the cemetery cronological limits. In this occasion, we publish a group of Iberian pottery and we value the complex and known phenomenon of the potteries imitation.

\section{INTRODUCCIÓN: LA NECRÓPOLIS DEL CORRAL DE SAUUS}

El yacimiento (fig. 1) se sitúa en una ladera del monte denominado El Castellaret, debido al hallazgo de los restos de un poblado ibérico correspondiente con probabilidad a la necrópolis (Fletcher y Pla, 1977, 56), a casi $8 \mathrm{~km}$ al Oeste de la actual población de Mogente (Valencia). Su excavación se llevó a cabo por parte del S.I.P. durante los setenta, bajo la dirección de D. Fletcher y E. Pla, con la directa intervención de J. Aparicio. La llamada necrópolis inferior (Aparicio, 1976; fig. 2) constituye, con $360 \mathrm{~m}^{2}$, prácticamente la totalidad del yaci-

\footnotetext{
${ }^{1}$ Este artículo se integra en el proyecto de investigación: «Tumbas destruidas y esculturas fragmentadas en la Cultura ibérica: el ejemplo del Corral de Saus de Moixent (Valencia)», dirigido por la Dra. C. Aranegui Gascó, que desarrollamos gracias a la concesión de una beca de F.P.I., otorgada por la Conselleria de Educació i Ciència de la Generalitat Valenciana. Asimismo, se enmarca en el proyecto denominado «La sociedad ibérica a través de sus cerámicas» (PB940977), subvencionado por la CICYT, en el que participamos.
}

miento, diferenciándose de la superior, situada en un aterrazamiento más alto, que tan sólo cuenta con $8 \mathrm{~m}^{2}$ de superficie excavada.

Las primeras noticias y publicaciones ven pronto la luz (Fletcher y Pla, 1972, 1974, 1977, entre otros), al compás, sin duda, de los excepcionales hallazgos monumentales procedentes de la «Tumba de las sirenas» y la «Tumba de las damitas». No obstante, esta necrópolis no ha contado con un estudio en profundidad, aunque es evidente el interés

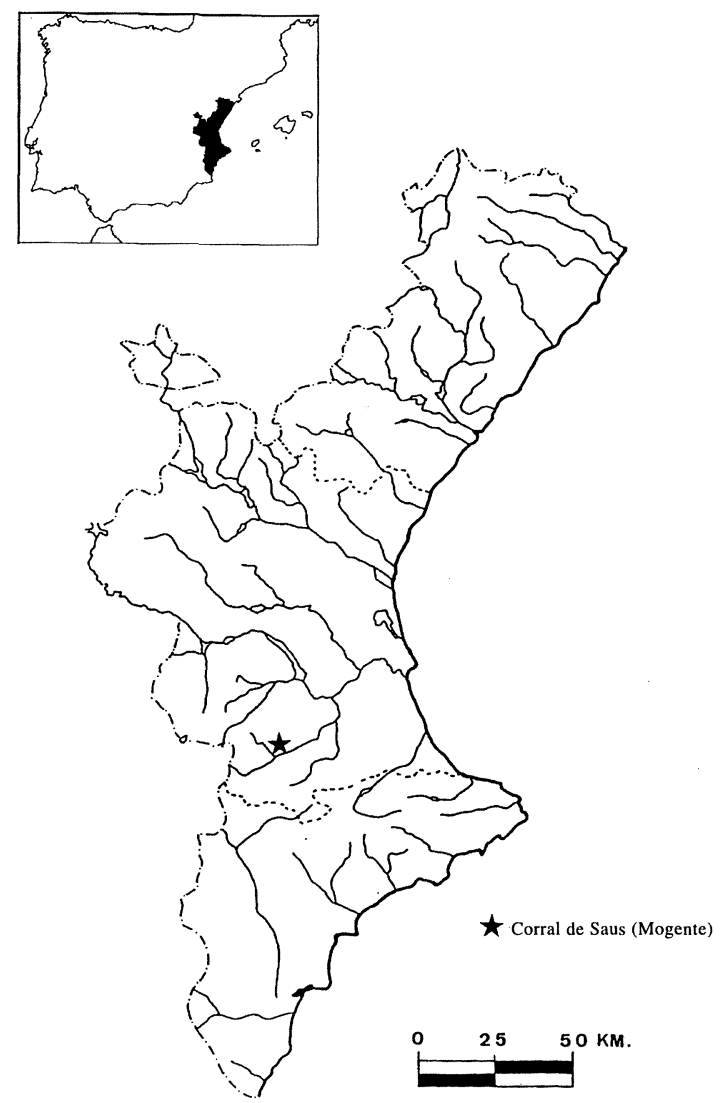

Figura 1.-Situación de la necrópolis ibérica del Corral de Saus (Mogente, Valencia). 


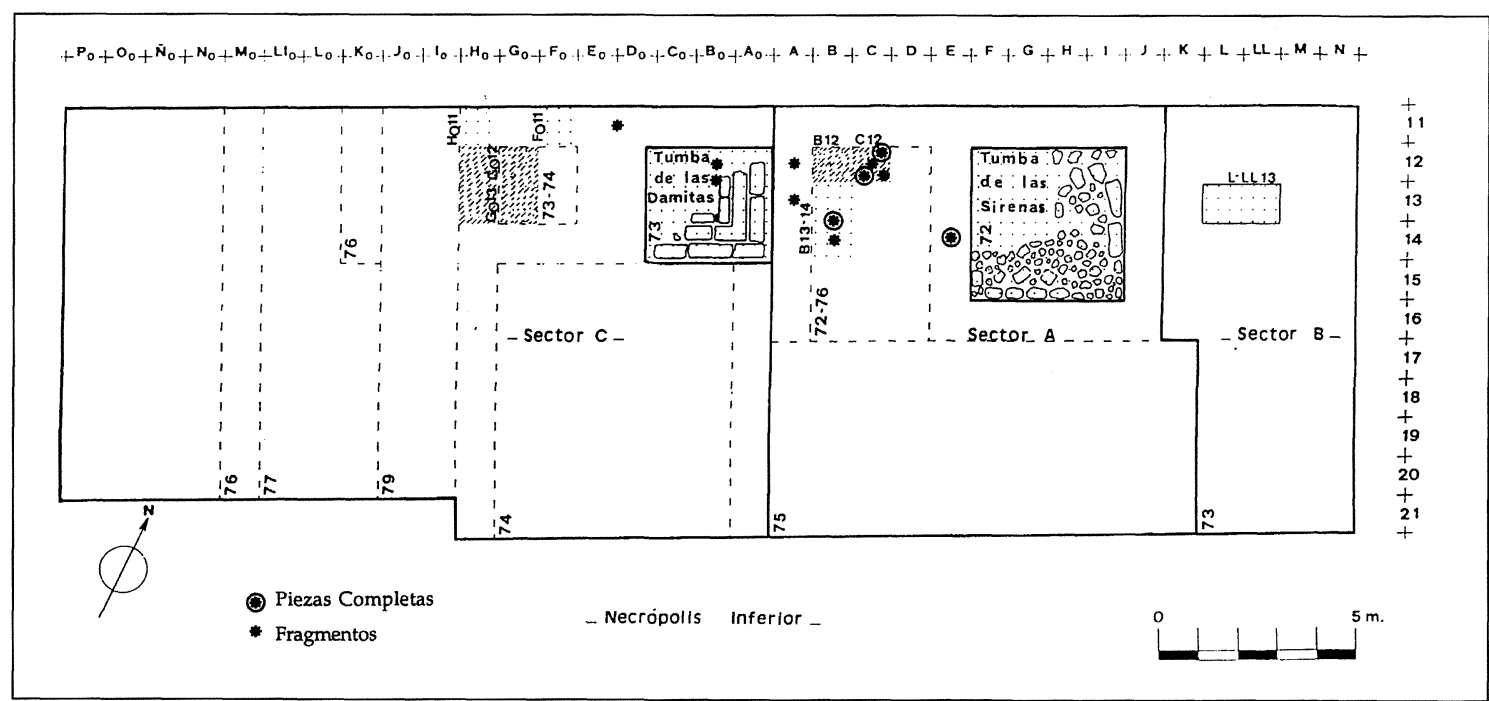

Figura 2.-Plano actualizado de zonas excavadas de la denominada necrópolis inferior del Corral de Saus (Aparicio, 1984, fig. 16). Localización de piezas completas y fragmentos de imitaciones de formas importadas en cerámica ibérica, procedentes de los ajuares funerarios del yacimiento.

de trabajos sobre temas puntuales como la propuesta de restitución del monumento conocido como pilar-estela (Almagro, 1987). En Corral de Saus, sin olvidar los problemas de remoción y descontextualización de parte de los ajuares, contamos con un gran conjunto material, prácticamente inédito, así como la documentación de una serie de enterramientos de los que algunos ofrecen fechas de deposición precisas. Hemos propuesto, tras el inventario y estudio de materiales realizado (Izquierdo, 1995a), unas cronologías centrales en torno a los ss. III y II a.C. para el yacimiento, con un hipotético momento anterior correspondiente al paisaje monumental atribuido a la necrópolis y una perduración hasta el cambio de era (Izquierdo, e.p.).

\section{LA CERÁMICA IBÉRICA}

La cerámica ibérica fina documentada manifiesta una original riqueza y variedad de formas y decoraciones con ejemplos extraordinarios tales como el vaso denominado «del héroe y la esfinge» (Izquierdo, 1995b). Siguiendo el criterio de Mata y Bonet (1992) para la clasificación del conjunto, hemos diferenciado 6 grupos funcionales dentro de la cerámica fina (clase A). Sin extendernos sobre el tema, puesto que la relación de porcentajes ha sido referida sintéticamente en otro trabajo (Izquierdo, e.p.), hemos de señalar que la vajilla de mesa es el grupo mejor y mayor representado, con 40 perfiles completos conservados, al que le siguen, en orden de importancia, el grupo de los recipientes de des- pensa, almacenaje y transporte, así como las imitaciones, cerrando la serie los artefactos cerámicos y los fragmentos de microvasos.

Centrándonos en el denominado grupo de imitaciones ${ }^{2}$, en el que se recogen piezas que imitan más o menos fielmente formas procedentes de diferentes ámbitos extrapeninsulares (Mata y Bonet, ·1992, 139 ), en el yacimiento objeto de nuestro estudio contamos con un pequeño pero interesante lote de cerámicas cuyas formas -y decoraciones en algún caso- se inspiran en prototipos mediterráneos y de manera más concreta, fundamentalmente, en formas griegas y suritálicas. El porcentaje obtenido para este grupo, en relación al total del inventario selectivo de cerámica ibérica, sin ser alto, es significativo (más del $6 \%$ ). Son cerámicas finas de cocción oxidante y pastas duras, con tonos que oscilan entre el anaranjado y el marrón claro, en su mayor parte pintadas en tonos marrón oscuro. Sus superficies se tratan, por lo general, con alisados. Las imitaciones documentadas son la copa-escifo, los platos F. 23 Lamb. -entre los que contamos con un plato de peces- y F. 36 Lamb., la cratera, además de otras formas con menor representación.

En otro orden de cosas, antes de detenernos en las propias cerámicas, hemos de señalar el interés que supone, para una adecuada comprensión de las piezas que presentamos, la integración del análisis

${ }^{2}$ Agradecemos al Dr. R. Olmos Romera sus apreciaciones, comentarios y amabilidad en la revisión del texto de este artículo. 
iconográfico con el soporte tipológico utilizado, sin prescindir del contexto cronológico-cultural de las mismas. Por otro lado, de cara a la consulta de las características individualizadas de cada pieza (localización, dimensiones, pastas, superficies, etc.), véase la tabla 1.

\section{Copas-Escifos (fig. 3, 1 y 2)}

Tres piezas, además de pequeños fragmentos, han sido identificadas como imitación de la copa griega con asas (Aranegui y Pla, 1981, F. 11a; Aranegui y Pérez Ballester, 1989), forma de frecuente aparición en tierras de Valencia y Murcia. Son copas que presentan de manera general, un borde saliente, base o pie anillado y asas horizontales de sección circular. Sus perfiles son de tendencia hemiesférica (fig. 3, 1) o carenada (fig. 3, 2). Las dimensiones son muy similares $-\varnothing$ boca de $11 \mathrm{~cm}$ en todos los casos - y las pastas, de cocción homogénea (v. tabla 1). En los dos ejemplos ilustrados hemos observado huellas de contacto con el fuego en sus superfi- cies. La decoración es pintada en estilo geométrico y se adapta a la articulación de la forma y partes estructurales del vaso. Así, el labio, la zona de las asas y el pie son destacados a través de bandas decoradas enmarcadas por filetes. Los motivos geométricos representados son: trazos verticales irregulares en el borde interno, arcos de círculo y semicírculos concéntricos en la superficie externa (fig. 3,1 ) o arcos de círculo y líneas onduladas paralelas (fig. 3, 2).

Las tres imitaciones de copas pertenecen a cremaciones distintas (fig. 2) datadas, a través de la presencia de cerámicas importadas de barniz negro, de manera aproximada en torno a la primera mitad del s. III a.C. El primer ejemplo (fig. 3,1 ) se adscribe a la «incineración $\mathrm{n}^{\circ} 4$ » $^{3}$ «en caja o cista» de la

\footnotetext{
${ }^{3}$ Por cuestiones de espacio no describiremos los ajuares funerarios en su totalidad. La «incineración $\mathrm{n}^{\circ} 4$ » contaba además con una tinajilla con hombro bitroncocónica y decoración geométrica, un pequeño caliciforme de perfil carenado, así como fragmentos de otros tipos cerámicos - tinaja, plato, pátera y botellita-, una lámina de bronce y dos fragmentos indeterminados de hierro (Izquierdo, 1995a, T. I, 263-264).
}

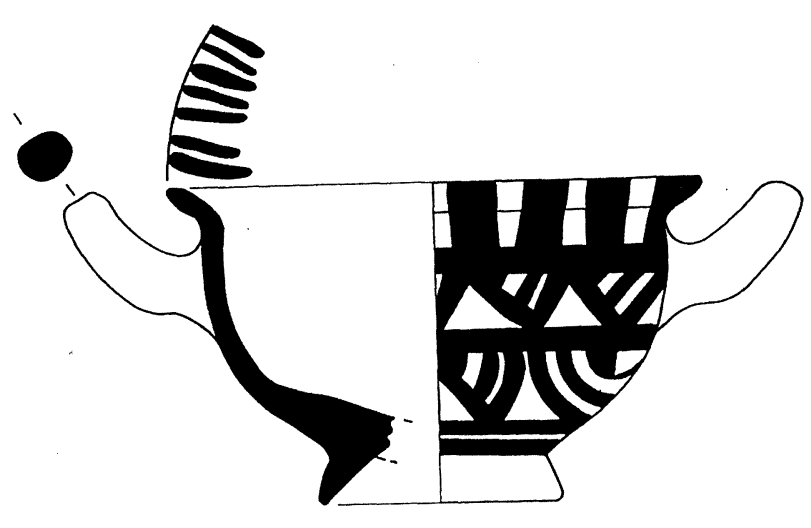

1
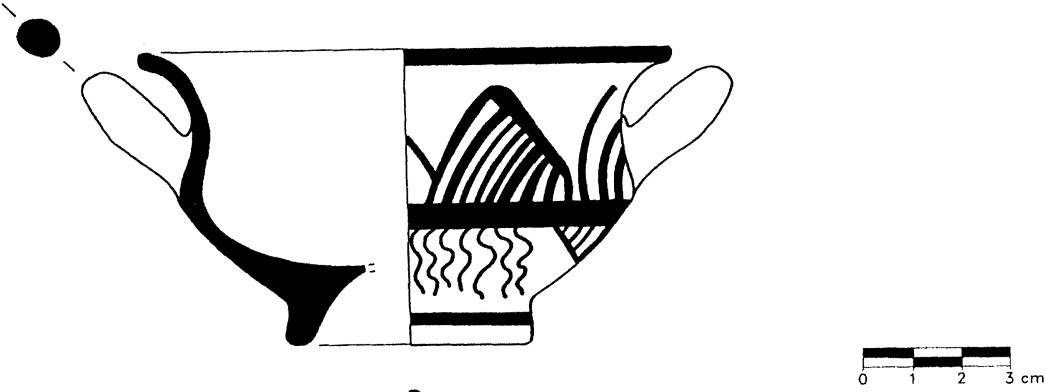

Figura 3.-1 y 2, copas con asas ibéricas con decoración pintada geométrica. 
denominada necrópolis superior (Aparicio, 1976). Como elemento de datación, cabe citar el hallazgo de una base fragmentada F. 27 a/b Lamb./ F-2784 (Izquierdo, 1995a, T. II, fig. 77, 4) del taller itálico de «pequeñas estampillas» (Morel, 1969; Sanmartí, 1973; Pérez Ballester, 1987) con rosetas impresas en relieve en su fondo interno. La segunda copa (fig. 3, 2) pertenece al singular conjunto C-12 (sector $\mathrm{A})^{4}$ de la necrópolis inferior, rico en hallazgos, que posteriormente trataremos, ya que a esta copa se suma el plato de peces, un fragmento de imitación de cratera y otro de vaso plástico (v. infra). Una pátera F. 28c Lamb./ F-2648 (Izquierdo, 1995a, T. II, fig. 77,1$)$ con palmeta impresa en relieve en su fondo interno, producción posiblemente del taller de Rosas (Sanmartí, 1978), fecha el conjunto. El tercer ejemplo pertenece al conjunto B13-14 (sector A) ${ }^{5}$, datado por una paterita de barniz negro F. 21/ 25 Lamb./ F-2714 (Izquierdo, 1995a, T. II, fig. 77, 2) con estampilla impresa en relieve, de compleja adscripción a un taller concreto.

En líneas generales, este tipo de imitaciones se ha documentado en el cuadrante Sureste peninsular, en el área murciana y tierras valencianas, tanto en necrópolis -El Cigarralejo, Cabecico del Tesoro, Cabezo Lucero o La Albufereta-, como en poblados - Castillico de las Peñas, Bolbax de Cieza, La Bastida de les Alcuses, Los Villares, Puntal dels Llops, La Serreta o el Tossal de San Miguel de Liria ${ }^{6}$.

\footnotetext{
${ }^{4} \mathrm{El}$ conjunto $\mathrm{C}-12$ cuenta además con un plato de borde exvasado, sin diferenciar, decorado con pintura monócroma de estilo geométrico con rombos en su superficie interior y semicírculos concéntricos en la exterior, así como pequeños fragmentos de otras formas ibéricas - tinajilla, jarro, caliciforme, plato, pátera y botella-. Contenía, asimismo, una lámina rectangular de hierro y un pequeño fragmento de terracota indeterminado (Izquierdo, 1995a, T. I, 253-254).

${ }^{5}$ El conjunto B13-14 se completa con dos platos de borde exvasado de ala ancha y una pátera, decorados con pintura geométrica, así como pequeños fragmentos de tinaja y jarro de boca trilobulada. Otros elementos son un fragmento de lanza de hierro, lámina y fragmentos indeterminados del mismo material. Distintos materiales como la terracota -un pequeño fragmento- o un nodulito de sílex, además de restos de macrofauna, fueron asociados al enterramiento (Izquierdo, 1995a, T. I, 252-253)

6 Véase para la provincia de Murcia: Cuadrado, 1972 136, tabla XVII, fig. 164.32; Lillo, 1981, 241, 262, figs. Peñ. X, 3-4 y Bol. VII, 1; Page, 1984, 82-83 y 89 figs. 9.6, 9.7, 9.9, 9.10, 9.12, 10.1; Asimismo, para Alicante, Nordström 1969-1973, 32, fig. 1; Llobregat, 1972, 182, fig. 98.5; Pericot, 1979, 50, fig. 63; Page, 1984, fig. 10.2, 10.3; Aranegui Jodin, Llobregat, Rouillard y Uroz, 1993, 108-110; y para Valencia, Fletcher et alii, 1969, 113, 119-120, 137, figs. 2, 3 , 5 y 7; Aranegui y Pla, 1981, 82 y 102; Bonet y Mata, 1981, 91, fig. 43; Page, 1984, figs. 10.10, 11.4 y Ballester et alii, 1954, 32, lám. XXVIII, 5; Mata, 1991, 98, fig. 53; Bonet, 1993, 472, fig. 56
}

\section{Platos}

\section{II.1. Plato de peces (fig. 4)}

A la citada copa-escifo (fig. 3,2 ) se asocia un plato de peces, cuya restitución ha sido posible tras la realización del inventario de materiales, aunque la pieza no se halla completa ${ }^{7}$. Con respecto a su contexto en la necrópolis (fig. 2), este plato apareció asociado al citado conjunto C-12 (v. supra) datado en torno a la primera mitad del s. III a.C. El plato se inspira en la forma ática, pero sin la cazoleta central característica del tipo, con el borde pendiente $(26 \mathrm{~cm}$. de $\Delta$ de boca, v. tabla 2$)$.

El plato se decora totalmente con figuración en la superficie interna, flores y roleos en la externa y motivos geométricos en el borde externo. La franja con decoración figurada zoomorfa interna, enmarcada con motivos geométricos — banda y filete-, muestra el cuerpo incompleto de tres peces - del tercero únicamente se conserva el ojo-, que nadan de derecha a izquierda. Los peces giran en círculo, separados por estilizaciones vegetales: flor acorazonada, hojas, espirales, así como brotes, expresando la idea del mar como fecundidad. Se representa su interior, como es frecuente en las figuraciones de animales en el mundo ibérico y, en un caso, tal vez la espina. No hay una repetición idéntica, por lo menos en los dos animales conservados, puesto que los motivos son distintos. Existe, pues, una interesante variación animal intencionada. Por su parte, la cazoleta podría ser sugerida a través de los motivos geométricos —filete y banda - pintados centrales. La decoración exterior, por otro lado, muestra un exuberante friso vegetal de brotes y espirales, enmarcado por motivos geométricos. Finalmente, el labio pendiente exterior se decora con triángulos pintados.

Es significativa la combinación de peces en su cara interna con representaciones vegetales en la externa, repetida en las decoraciones cerámicas de Liria (Aranegui, Mata, Pérez Ballester y Martí, e.p.). Un trabajo reciente ha propuesto la interpretación de estos platos como exponente de unas creencias en relación a una concepción del viaje al más allá, difundidas por todo el Mediterráneo ya en el s. IV a.C. que penetran en la sociedad ibérica hacia el s. III a.C. (Aranegui, e.p.). Con respecto a la forma, nos parece interesante la propuesta de separar los platos de peces pintados sin cazoleta de los «de pescado, con cazoleta» que no presentan esta com-

7 Uno de los fragmentos de esta interesante pieza fue publicado por Aparicio (1976; idem, 1982, 46, fig. 5) bajo el nombre del yacimiento «Enguerina» y posteriormente recogido en el catálogo de V. Page (1984, 112, fig. 16.1). 


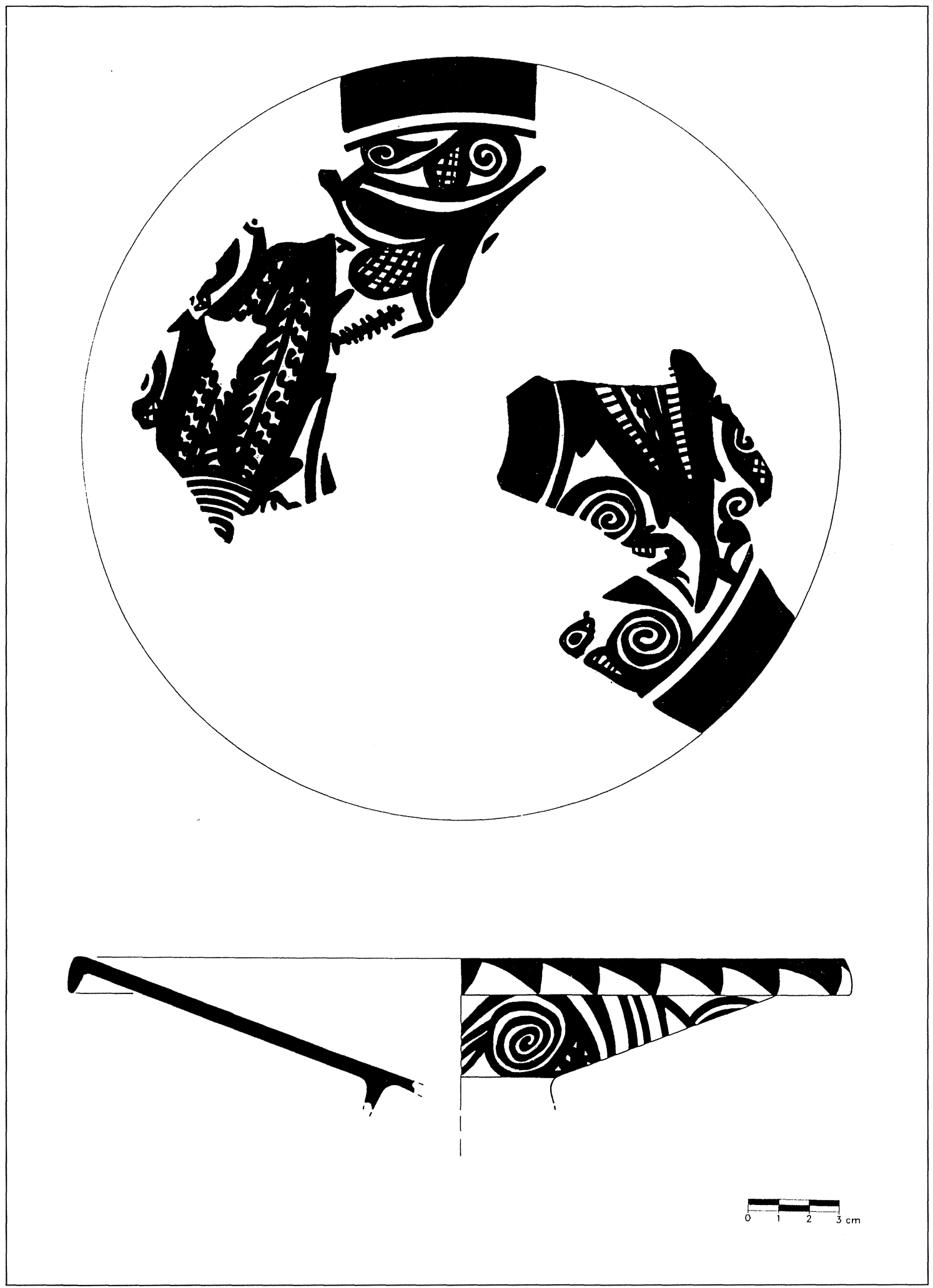

Figura 4.-Plato de peces ibérico. 
binación de motivos, ya que los primeros se asocian cada vez más al fenómeno de las representaciones simbólicas de la sociedad ibérica, perdiendo la función de elemento de la vida cotidiana, debido a su decoración ${ }^{8}$. A su vez, ya la composición con temas marinos que decora la fíala argéntea de Tivissa (Serra Ráfols, 1941), orientaba esta interpretación singular. En este sentido cabe citar la exuberancia de la naturaleza plasmada y el simbolismo del mundo vegetal, posible reflejo de un ambiente acuático, aspecto comentado y analizado en otros vasos (Olmos, 1989). Por último, los platos de peces, los más directamente imitados de la vajilla ática y suditálica, son conocidos en el ámbito de la cultura ibérica, y concretamente en las provincias de Castellón, Valencia, Alicante, Albacete y Murcia ${ }^{9}$.

\section{II.2. Posible plato F. 23 Lamb. con decoración pintada geométrica (fig. 5, 1)}

Sin mantener la cazoleta, aunque conservando su característico labio pendiente, se ha conservado un ejemplar que presenta decoración pintada de estilo geométrico en su superficie interior y labio, permaneciendo la superficie externa lisa. Este posible plato ${ }^{10}$, de finas secciones (v. tabla 1 ), se decora con

8 Véase al respecto, el trabajo de McPhee y Trendall (1987) en el que se observa el uso de los platos de peces como posible ajuar funerario en Grecia, el Mar Negro, la Magna Grecia y Sicilia, donde es el simbolismo marítimo del pez lo que cuenta. Su diseño ya no tiene nada que ver con la alimentación sino que evoca la travesía que el difunto emprende a través del océano, de ahí que estos platos de peces parecen distinguirse de los platos de pescado. A los primeros ya no les hace falta la cazoleta - no la tienen- porque su finalidad es simbólico-ritual.

${ }^{9}$ Con ejemplos, recogidos por Aranegui (e.p.), tales como el de La Peña de las Majadas (Sarrión, 1978, lám. III, 1 y 2), la Cueva del Mal Paso (Fletcher, 1954, fig. 16), Tossal de la Cala de Benidorm (Nordström, 1969-1973, fig. 46; Page, 1984, fig. 16), San Miguel de Liria (Pericot, 1979, fig. 218; Page, 1984, fig. 17, lám. IV.2; Bonet, 1993, fig. 86; Aranegui, Mata, Pérez Ballester y Martí, e.p.) con platos de peces así como la fíala pintada con este mismo motivo; La Covalta (Page, 1984, 112, fig. 16, 3; Raga, 1994, lám. 100) y Los Villares (Mata, 1991, fig. 74). Igualmente se documentan en el área albaceteña, tal es el caso del plato de la Hoya de Santa Ana (Albacete) (Pericot, 1979, 35, fig. 40, Page, 1984, 111) o el Cerro de los Santos (Abad y Sanz, 1995) y Murcia, como en Archena (Lillo, 1981, 321, fig. Arc-1).

${ }^{10}$ Otra posibilidad que no puede ser obviada es la clasificación del tipo con función de tapadera de otro recipiente. En este sentido, dicha funcionalidad sería sugerida en el conjunto de platos de Corral de Saus a través, por una parte, de la presencia de una profusa y doble decoración -en sus superficies interior y exterior-, así como por la ausencia de desgaste de la cara interna, bien conservada en gran parte de los casos. Asimismo, su utilización como tapaderas fue evidenciada in situ durante el proceso de excavación (Aparicio, 1976; idem, 1982, lám. XII). triángulos seriados en el exterior del labio y su superficie interna muestra una banda posiblemente de semicírculos concéntricos con punto central - la pintura se halla muy deteriorada - enmarcada entre la ya clásica combinación de filete- banda-filete. Este plato no posee una localización espacial precisa (cuadrículas Bo-Ho 11, sector C) aunque la referencia indicada nos sitúa de nuevo al N-NW de la «Tumba de las damitas». En el ámbito de la Edetania y Contestania se ha recogido una docena de estos platos con decoración pintada geométrica ${ }^{11}$.

\section{II.3. Plato F. 36 Lamb. con decoración pintada geométrica (fig. 5, 2)}

Un ejemplar con labio curvo y ligeramente pendiente, aunque de pequeñas dimensiones, podría considerarse como afín al modelo companiense. Se trata de un plato que presenta dos orificios de suspensión en el labio y evidentes huellas de contacto con el fuego, decorado en su totalidad con pintura de estilo geométrico (v. tabla 1). Los motivos geométricos plasmados son dos bandas seriadas paralelas de semicírculos concéntricos con punto central y arcos de círculo concéntricos, enmarcadas por filetes - en el interior-; así como banda de arcos de círculo concéntricos, en alternancia con líneas onduladas paralelas verticales o «melenas». Este plato fue hallado junto a la «Tumba de las sirenas» (cuadrícula E-14, sector A) (fig. 2). No podemos olvidar que una de las escasas piezas de importación completas conservadas en Corral de Saus, además de abundantes pequeños fragmentos de borde, pertenecen a la F. 36 Lamb./ F-1312. A modo de paralelos de estos platos pintados con decoración geométrica, poseemos ejemplos cercanos, de nuevo, en la Edetania y Contestania ${ }^{12}$.

\section{II.4. Platos F. 36 Lamb. sin decoración (fig. 5, 3 y 4 )}

Se han documentado una serie de pequeños fragmentos (28) de labio curvo y pendiente, proba-

${ }^{11}$ Procedentes de los yacimientos siguientes: Tossal de la Cala, Tossal de Manises, Puntal dels Llops, La Serreta, Castellet de Bernabé, Los Villares y el Tossal de Sant Miquel, recogidos por Bonet y Mata $(1988,10)$. Del mismo modo, en Murcia se han documentado imitaciones decoradas de este tipo, recopiladas por Page $(1984,113-117)$. Estas piezas se sitúan en un arco cronológico que va desde la primera mitad del s. IV a.C. a la primera mitad del s. III a.C. (Aranegui y Pérez Ballester, 1989, 242).

${ }^{12}$ En los yacimientos de Los Villares, Puntal dels Llops, La Serreta y el Tossal de la Cala, según Bonet y Mata $(1988,12)$ 


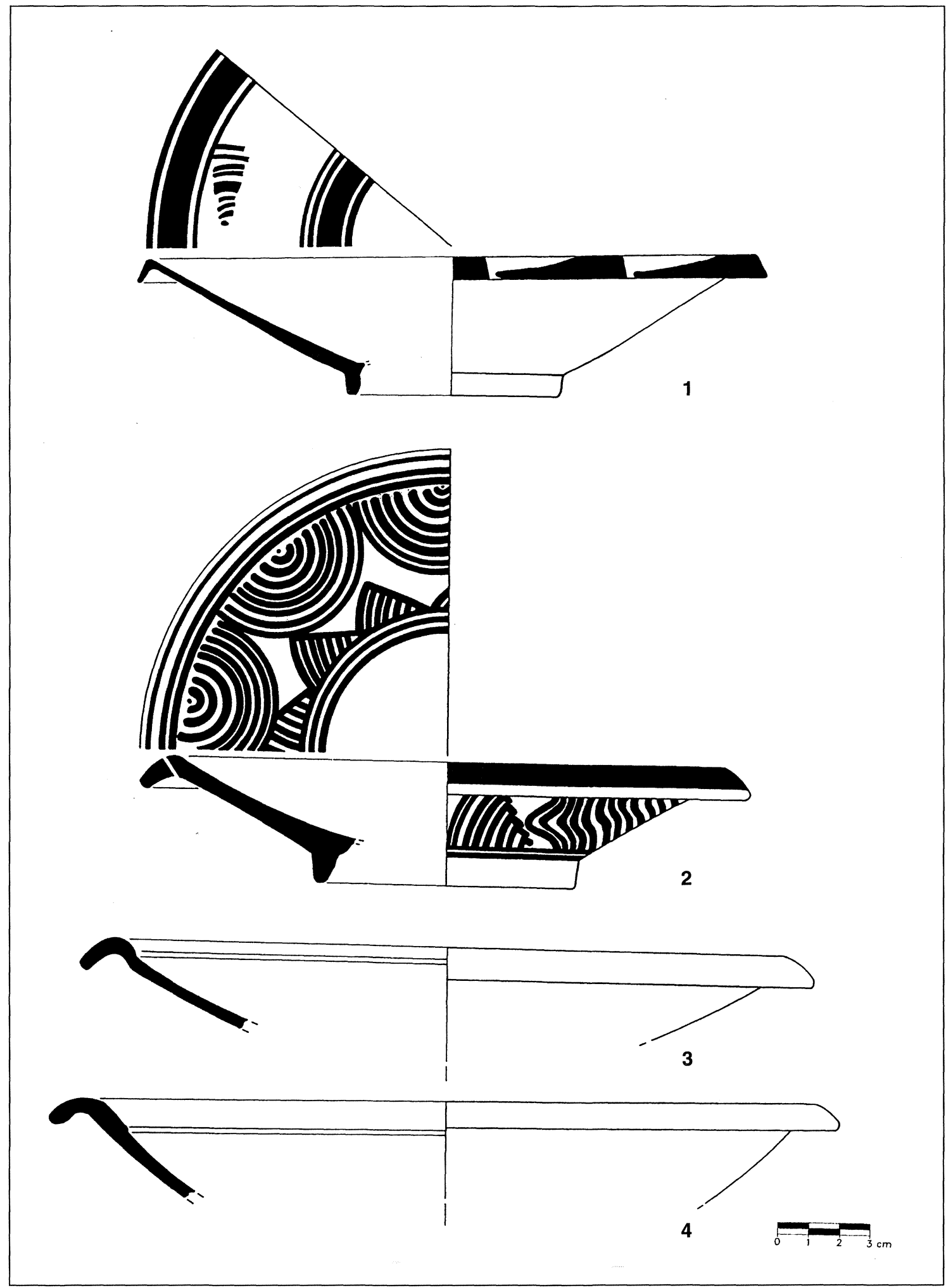

Figura 5.-1, posible plato o tapadera ibérica con decoración pintada geométrica; 2, plato ibérico con decoración pintada geométrica; 3 y 4, platos ibéricos sin decoración. 
ble imitación de platos campanienses F. 36 Lamb. Son fragmentos de reducidas dimensiones, lisos, que pertenecen en su mayor parte a la clase fina de cocción oxidante (27). Presentamos dos ejemplos que han permitido la obtención de su $\Delta$ de boca (26 y $28 \mathrm{~cm}$ respectivamente). Al respecto hay que señalar que una de las escasas piezas de importación completas conservadas en el yacimiento es precisamente una F. 36 Lamb. / F-1312 de campaniense A, de la primera mitad del s. II a.C. En relación al hallazgo de las piezas en la necrópolis, el primer ejemplo (fig. 5, 3) aparece vinculado - aunque no directamente ${ }^{13}$ - con la segunda gran tumba de empedrado tumular excavada en el yacimiento conocida como «de las damitas» (Fletcher y Pla, 1974) (fig. 2). Por su parte, la segunda pieza (fig. 5, 4) fue hallada en la cuadrícula A-12 del sector A, sin un contexto definido. Contamos con numerosos ejemplos de estos platos lisos, imitaciones de formas ya tardías en tierras valencianas y de Murcia ${ }^{14}$.

\section{Crateras y cántaros (figs. 6, 7, 8, 9 y 10)}

Presentamos en este trabajo algunos vasos (v. tablas 1 y 2) que, aun siendo prudentes, puesto que no conservamos ningún ejemplar completo, podrían asociarse al grupo de imitaciones de crateras, entre los que contamos con ejemplos interesantes. En primer lugar comentaremos el hallazgo de un vaso fragmentado (fig. 6), único ejemplo con policromía del yacimiento, de boca ancha $(32 \mathrm{~cm}$ de $\varnothing)$ y borde saliente, con cuerpo de tendencia acampanada. A esta pieza se asocia un pequeño fragmento de asa de sección circular. Su singularidad se manifiesta en la propia forma, sus dimensiones, la técnica de la policromía y la articulación de la decoración a la estructura del vaso. Asimismo, es interesante el cambio de escala que se opera con respecto al modelo original griego de dimensiones canónicas. Esta reducción del tamaño de la pieza podría implicar el uso de la cratera como vaso individual o un cambio de significado.

${ }^{13}$ La referencia concreta de la pieza indica su pertenencia al Sector C, talud testigo de las cuadrículas Bo12, Bo13 y Bo14 (8-VI-1973), que forman parte directamente de la estructura conocida como «Tumba de las damitas», tal y como puede observarse en el plano del yacimiento (fig. 2). No obstante, hemos de señalar nuestro desconocimiento de la ubicación exacta de la pieza, bien formando parte del ajuar de la propia tumba, de su empedrado o bien perteneciente a un momento posterior indeterminado.

${ }^{14}$ Como en La Serreta, La Alcudia, el Pico de los Ajos y Sagunto, en el ámbito de la Edetania y la Contestania (Aranegui, 1970; Bonet y Mata, 1988, 12), así como en Cabecico del Tesoro de Verdolay en Murcia (Page, 1984, 152, figs. 24, 3 y 4).
La superficie interna se decora con pintura geométrica a base de filetes paralelos de color marón oscuro. La exterior presenta una decoración polícroma combinando el color marrón oscuro característico en todos los motivos principales - filetes que enmarcan, de arriba abajo, una guirnalda, una banda de ovas seriadas con botón central y roleos-, el color blanco - a modo de fondo de las bandas con guirnalda y ovas- y el color rojizo -rellenando los roleos seriados y el motivo geométrico final-. Este vaso se halla fragmentado y no es posible reconocer el resto de la composición decorativa. Parece apreciarse finalmente, la parte superior de lo que podría ser una nueva serie de roleos.

La tipología del vaso, unida a los temas decorativos plasmados - guirnalda, ovas, roleos- evidencian claros referentes en las cerámicas griegas y suritálicas. Así, es interesante citar la aparición de ovas decorando las asas en crateras griegas del s. IV a.C. No obstante, destaca, en primer lugar, la hipotética sustitución que se opera con respecto a los característicos temas figurados que decoran las crateras áticas por composiciones donde prima el carácter ornamental, vegetal y geométrico. Recordamos en este punto las palabras de R. Olmos a propósito del vaso de Santa Catalina del Monte (Verdolay, Murcia) que, por otra parte, ofrece paralelos en la selección de los motivos decorativos vegetales con la pieza de Corral de Saus «(...) no es el arte ibérico un arte antropomórfico sino esencialmente simbólico y globalizador de la naturaleza» (Olmos, 1987, 24). Así, observamos que los motivos geométricos - filetes- enmarcan frisos horizontales superpuestos en donde temas vegetales - guirnalda, roleos - imprimen un nuevo dinamismo y movimiento a la composición. La disposición de elementos en franjas horizontales es común con el estilo puramente geométrico, aunque los ritmos y las sucesiones en el espacio, aún siendo ordenadas, adoptan una nueva dimensión donde impera la sensación de movimiento a través de líneas curvas fundamentalmente, con que se representan estos motivos vegetales y florales. Testimonio de ese gusto por plasmar formas que derivan de la naturaleza, los temas vegetales comienzan a emplearse en un momento todavía impreciso del s. III a.C. en los yacimientos ibéricos, según C. Aranegui (1975, 50), de manera simultánea a la aparición de figuraciones zoomorfas y antropomorfas (Aranegui, Bonet, Martí, Mata y Pérez Ballester, e.p.). Se integran con los clásicos motivos geométricos y otros nuevos que se suman al repertorio existente, en nuevas composiciones de ritmos libres y dinámicos, característica de vasos exclusivos para usos destacados o significativos, 


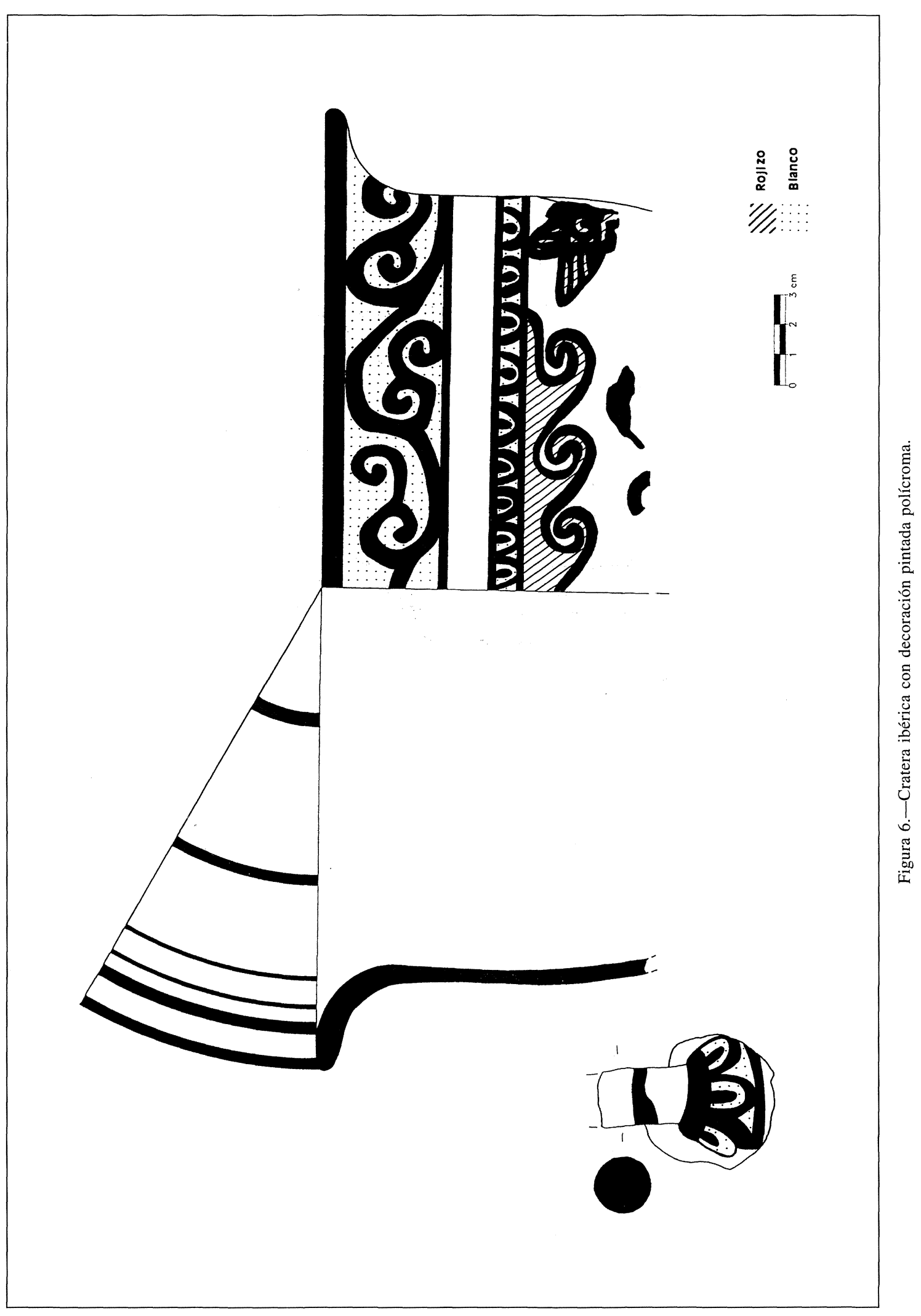


como se desprende de su menor frecuencia y convivencia con los decorados con temas complejos. F. Lissarrague (1989, 267-269) afirma que se imitaron más las formas de los vasos griegos que sus decoraciones; en este ejemplo tendríamos una típica síntesis ibérica.

Desde el punto de vista de la técnica, el tipo de decoración que plasma esta pieza no se parece a la policromía que tradicionalmente han manifestado cerámicas de filiación fenicia o del horizonte ibérico antiguo donde el negro y el rojizo son los colores básicos y los temas repiten esquemas geométricos de bandas y filetes combinados en su mayor parte. Más bien los motivos se acercan a la decoración bícroma y polícroma de fragmentos hallados en La Covalta (Raga, 1994, 140) o El Amarejo (Broncano, 1989, 219-223), yacimiento éste último donde el tema de los roleos ya se ha documentado con anterioridad en su depósito votivo (idem, 1989, 156, fig. $\left.103, \mathrm{n}^{\circ} 147\right)$ con bicromía, así como en diversos fragmentos con decoración monócroma (Broncano y Blánquez, 1985, 99, fig. 42, n 51). Asimismo, la utilización del color blanco nos introduce en un ambiente ibérico mayor. Su aparición en el mundo de las necrópolis ${ }^{15}$, asociada a otras características, puede sugerir su definición como vasos de encargo (Olmos, 1987). Se trata de vasos que no tienen un uso cotidiano, sino que son de lujo y, para el caso de Corral de Saus, poseen tal vez, un sentido funerario.

Por otro lado, los temas decorativos de la pieza recuerdan - como hemos señalado - las bandas de roleos vegetales del vaso globular hallado en el Cero de Santa Catalina del Monte, donde además aparece representada una escena con dos personajes posiblemente femeninos enfrentados (Jorge, 1969, 200-204) cuya cronología se ha situado en torno al s. III a.C. (Olmos, 1987, 23). Se trata, como podemos observar, de decoraciones infrecuentes en el ámbito del País Valenciano, a pesar de que diversos estudios se han dedicado a señalar las cerámicas con decoración pintada polícroma (Aranegui,1974; Oliver, 1982-1983, entre otros).

La pieza no aparece asociada a ningún enterramiento concreto, sin embargo, la referencia espacial indicada (cuadrículas Do-Eo11, sector C) (fig. 2) nos sitúa en un espacio inmediato al NW de la «Tumba de las damitas» por una parte, y el enterra-

${ }^{15}$ Véase como ejemplos, el clásico conjunto de Baza (Granada) (Presedo Velo, 1982) o en Albacete, los recientes e interesantes hallazgos de la necrópolis de El Salobral (Blánquez, 1995, 56), sobre piezas ibéricas de inspiración clásica. miento Fo11 ${ }^{16}$, en el que se halló el conocido caliciforme globular con decoración de estilo Elche-Archena (Aparicio, 1977, lám. XIV; Izquierdo, 1995a, v. II, fig. 36, 1).

Más incompletos se conservan dos vasos (fig. 7 1 y 2 ) de boca ancha ( $26 \mathrm{~cm}$ de $\Delta$ en ambos casos) y borde saliente (v. tabla 2). Su identificación como posible imitación de cratera se debe a su característico perfil y la decoración de su superficie externa, con paralelos -en la técnica y los temas representados- en el vaso con policromía que hemos comentado anteriormente (v. supra). La decoración de nuevo se adapta a la tectónica del vaso, combinando los colores marrón oscuro -en los temas principales - y blanco - a modo de fondo-. En ambos casos, motivos geométricos simples -filete (fig. 7, 1) y banda (fig. 7, 2) - decoran el borde interno de los vasos. El primer ejemplo (fig. 7,1 ) muestra en su superficie exterior filetes que enmarcan bandas horizontales con temas seriados de roleos y semicírculos con punto central. La pintura, en este caso, se halla mal conservada. La referencia contextual de esta pieza es vaga (cuadrículas G-H-I-J 16, sector A) ya que, si bien nos señala un espacio al $\mathrm{S}$ de la «Tumba de las sirenas», pocas orientaciones cronológicas nos ofrece. El segundo caso (fig. 7, 2) muestra también filetes que dan paso paso y enmarcan una banda con semicírculos seriados con punto central, a modo de ovas. A esta pieza se asocia un pequeño fragmento de galbo con la misma composición decorativa a la que se le añade una serie de líneas en zig-zag, dispuesta en una banda horizontal. En ambos vasos la pintura blanca acompaña la decoración principal que se realiza con el color marrón oscuro. Éste último ejemplo pertenece al ya conocido y singular enterramiento $\mathrm{C}-12$, en donde se hallaron las piezas descritas más arriba -imitación de copa con asas, plato de peces- (v. supra).

Igualmente se ha documentado un recipiente cerrado de perfil carenado y base indicada (fig. 7, 3), desafortunadamente sin referencia espacial, cuyo tipo no puede ser concretado. Posee una decoración pintada bícroma a base de motivos geométricos y vegetales, similar a los vasos descritos anteriormente con bicromía/policromía y que por ello presentamos en este punto. Se observa en la superficie exter-

\footnotetext{
${ }^{16}$ Asimismo, en las cuadrículas donde se documentó la pieza, se hallaron distintas producciones de cerámicas importadas que manifiestan la remoción de los materiales: una copa fragmentada de pie alto con asas, F. 68 Lamb./ F-3131 de campaniense A media por un lado, así como fragmentos del borde y galbo de una cratera ática de figuras rojas con la posible representación - dudosa debido a la gran fragmentación del vaso- de una escena dionisíaca (Izquierdo, 1995a)
} 


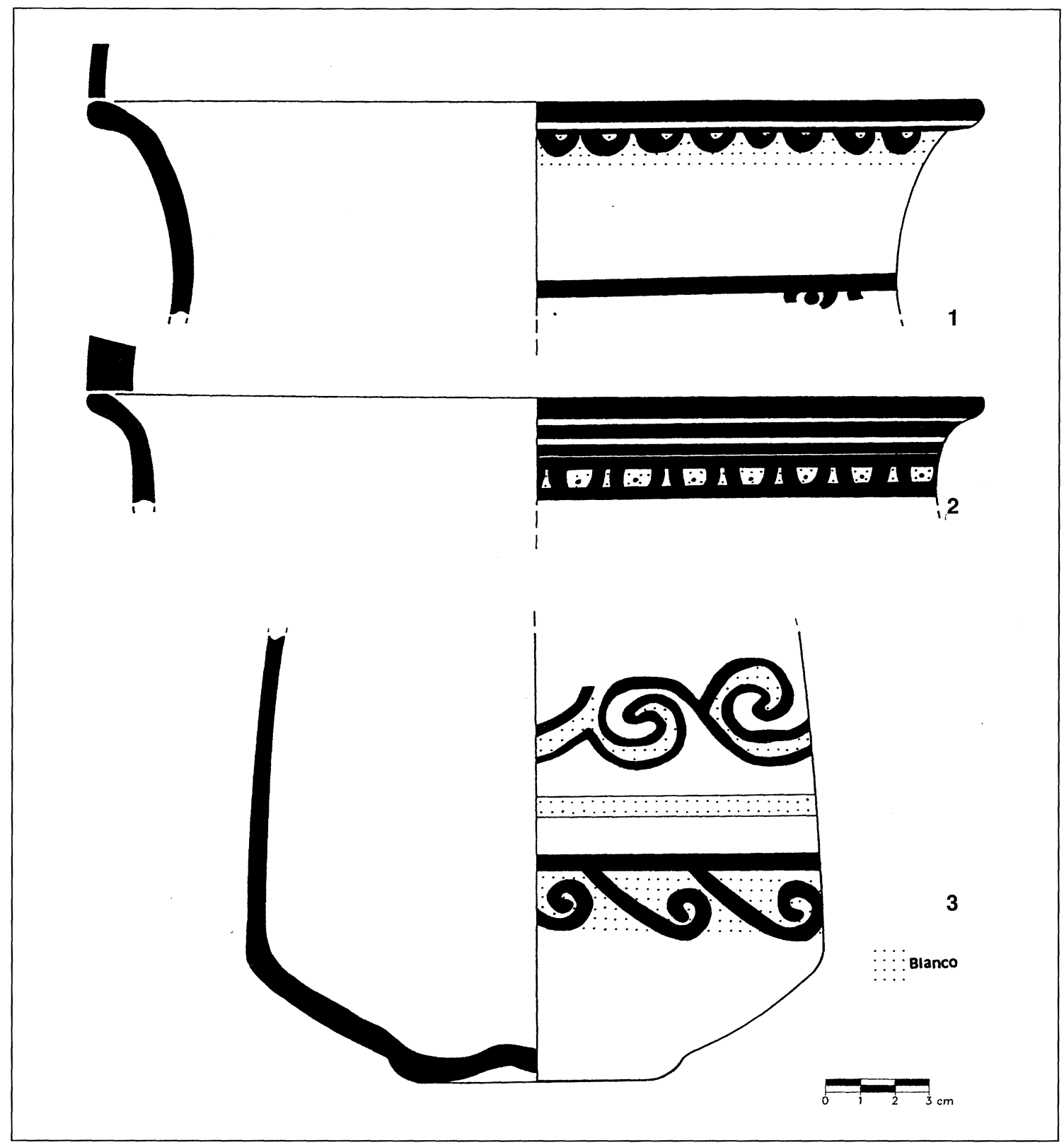

Figura 7.-1 y 2, crateras ibéricas con decoración pintada bícroma; 3, vaso cerrado con decoración pintada bícroma.

na, de arriba abajo, una guirnalda de pequeños roleos perfilados en color marrón oscuro con el interior relleno de pintura blanca. A continuación, un filete aislado, pintado en blanco, otro filete, esta vez en marrón oscuro, del que pende una banda de roleos, sobre el característico fondo de pintura blanca. Hemos considerado oportuno mostrar esta pieza fundamentalmente por su afinidad decorativa - técnica y estilística - con los ejemplos anteriores - sobre todo con la pieza polícroma-, aunque como he- mos señalado, desconocemos la forma a la que pertenece.

Las piezas polícromas del Corral de Saus no parecen corresponder al mismo horizonte cultural ni cronológico que señalan la bicromía y policromía andaluza, más bien, nuestros ejemplos se sitúan en una época más avanzada, documentada en Murcia y Albacete, principalmente. Nuestras conclusiones se hallan limitadas dada la escasez de estas producciones en el yacimiento, muy minoritarias en relación a 
la considerada cerámica típicamente ibérica y la inexistencia por otra parte, de un contexto cronológico-estratigráfico preciso que feche su deposición en las tumbas. Interesa, no obstante, destacar la singularidad de estas producciones en la necrópolis y, concretamente, la inserción del uso del color blanco en un contexto más amplio ibérico y mediterráneo.

Un interesante vaso abierto del que se conservan fragmentos del galbo, dotado de asas transversales, podría considerarse una imitación de cratera o de cántaro (fig. 8) (v. tabla 1). La asociación de su perfil, la forma del asa y su decoración original singularizan la pieza. La decoración pintada figurada de tipo zoomorfo es excepcional, a pesar del mal estado de conservación de la pintura, que no nos permite apreciar la totalidad del diseño. Sin embargo se puede observar la presencia -mediante la técnica del perfilado- de un jabalí (fig. 8, 1), representado
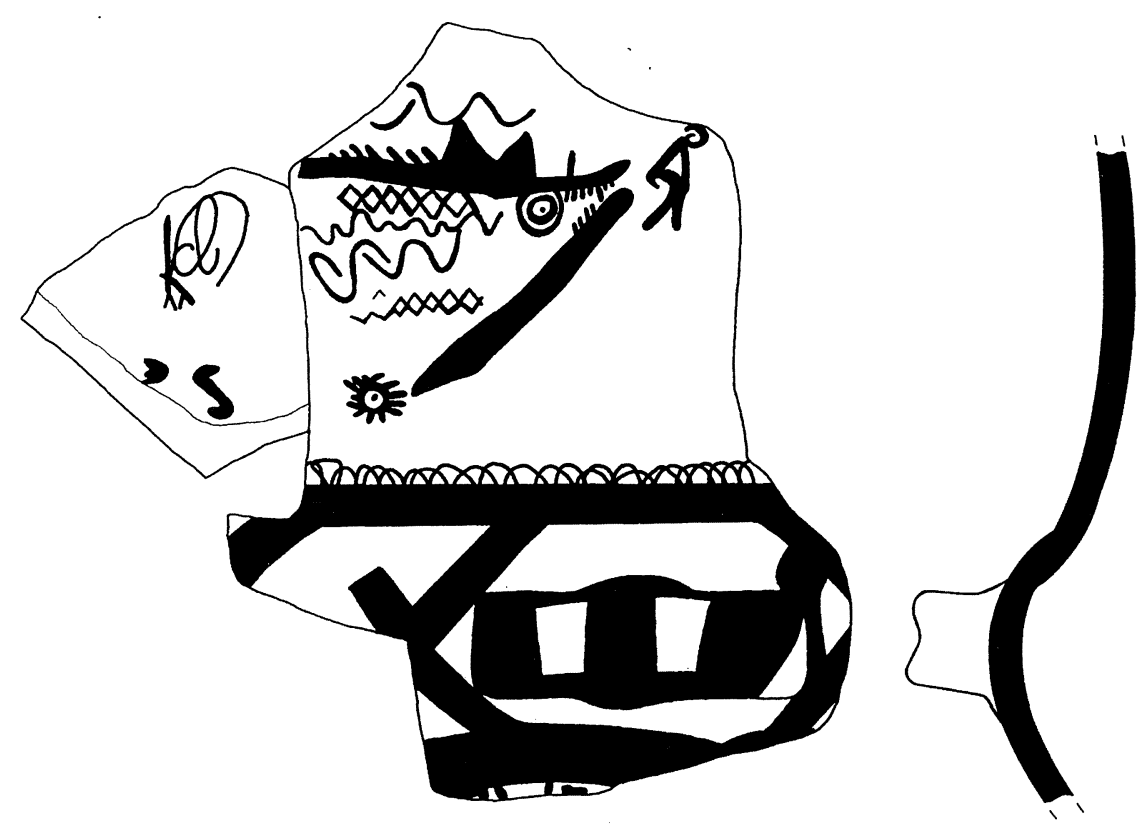

1
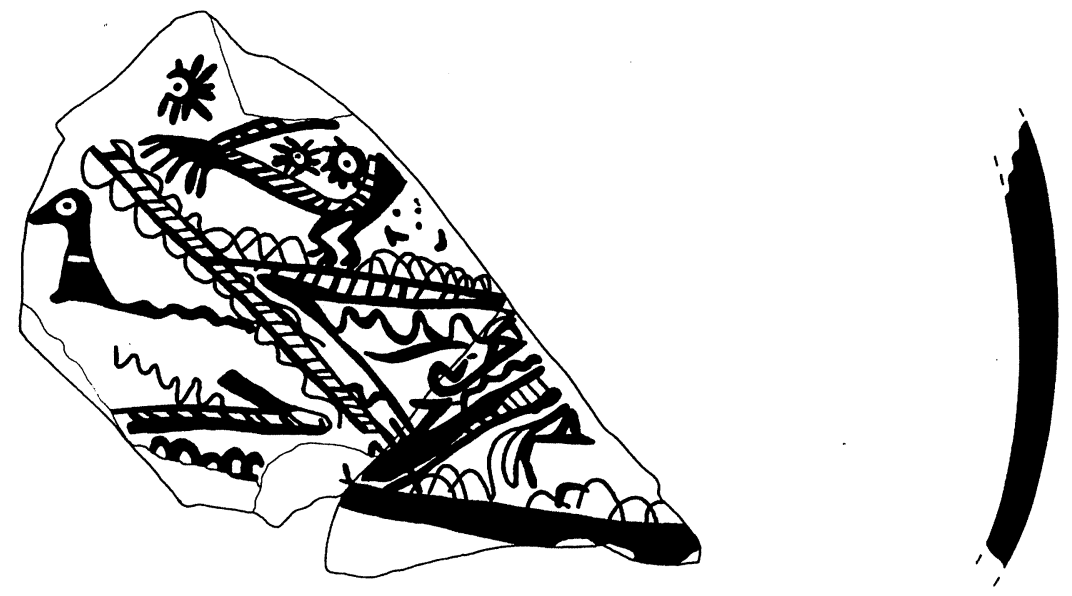

2

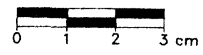

Figura 8. - 1 y 2, vaso abierto con decoración pintada figurada. 
con el cuerpo de perfil y el ojo de frente - dos circunferencias concéntricas con punto central-, en actitud amenazadora, con las fauces abiertas, colmillos visibles, orejas y crines del torso bien marcadas. Presenta el interior de su cuerpo decorado con motivos geométricos — series horizontales de retículas y líneas onduladas - aunque la pintura se halla perdida en parte. Otros fragmentos pertenecientes a esta pieza (fig. 8,2 ) muestran el desarrollo del galbo con más figuraciones zoomorfas, tales como dos aves, una de las cuales, ya conocida (Aparicio, 1982, fig. 7), permite apreciar motivos ornamentales en su interior a modo de «ojos estrellados». Se trata de uno de los ejemplos cerámicos con excepcional decoración figurada de tipo zoomorfo. La disposición de los motivos en espacios triangulares es conocida en el caso de Liria (Valencia). Es original la representación de ese hipotético jabalí, junto con las dos aves en un espacio compositivo compartimentado y decorado con temas geométricos que se disponen de manera abigarrada en una atmósfera casi asfixiante, confirmando ese gusto por la ornamentalización propio de las decoraciones cerámicas en el mundo ibérico. Por otra parte, el jabalí, símbolo en numerosos pueblos de la antigüedad de la fuerza y el valor, posee en el mundo ibérico fuertes connotaciones funerarias (Quesada, 1990, 47). Asimismo, aparece en las decoraciones de las cerámicas de Liria (Aranegui, Mata, Pérez Ballester y Martí, e.p.), así como en otras piezas típicamente ibéricas como la falcata decorada depositada en el S.I.P. (Aranegui, 1992). A pesar de no adscribirse a ningún enterramiento concreto de la necrópolis, esta pieza posee una referencia espacial que de nuevo nos conduce al entorno de las dos grandes tumbas. En este caso, nos situamos en la cuadrícula F11 del sector A, inmediatamente precedente - al N-de la «Tumba de las sirenas».

Otros fragmentos de borde de recipientes abiertos, cuya forma desconocemos, podrían estar en relación con vasos crateriformes, tal como apunta su aparición en otras necrópolis ibéricas como El Cigarralejo (Cuadrado, 1972 y 1987). En síntesis, se trata de bordes fragmentados de tipo saliente (fig. 9, 2 al 6) y moldurado (fig. 9, 1 y 7) que presentan decoración pintada monócroma de estilo geométrico en sus superficies exteriores, mostrando los característicos filetes horizontales aislados (fig. 9, 1, 3 y 5), bandas de líneas ondulantes (fig. 9, 2 y 7), en zig-zag combinadas con filetes (fig. 9, 4), o de roleos (fig. 9,6). Estas piezas plantean muchas dudas puesto que no conservamos grandes alturas que nos permitan reconocer su galbo. Así pues, diversas son las posibles opciones de clasificación que se nos presentan - ¿alguna variante del tipo de tinaja sin hombro, grandes tapaderas decoradas?- además de la ya planteada como imitaciones de crateras, por la que nos inclinamos. Pocas piezas poseen una referencia clara a nivel espacial, entre éstas, el encachado tumular de la gran estructura del sector A por un lado (fig. 9, 1) o la cuadrícula A-13 del citado sector (fig. 9, 2).

Se han documentado en la necrópolis, finalmente, tres fragmentos de asas en forma de voluta, que se asocian en general a vasos crateriformes. Del mismo modo, otra asa vertical de sección combinada -cuadrangular y trenzada- (fig. 10) pertenecería a una pieza de este tipo. Este fragmento de asa nos habla, a su vez, de la concepción analítica del proceso de elaboración cerámico en el mundo ibérico.

\section{Otras formas (fig. 11)}

Incluimos en este epígrafe otras formas imitadas de barniz negro que no cuentan - bien por el alto índice de fragmentación de las piezas, sus exiguas dimensiones o su propia escasez- con una adecuada representación, aunque documentan, de manera testimonial, la presencia de nuevas formas de origen mediterráneo en el yacimiento.

Diversos fragmentos de pequeñas dimensiones han sido catalogados como posibles imitaciones de vasos plásticos. Su clasificación inicial fue puesta en suspenso ante la difícil adscripción de estas piezas a una forma concreta. Sin embargo ante el hallazgo del ejemplo de mayores dimensiones (fig. $11,4)$ a modo de cola y arranque del cuerpo y pata de un recipiente cerámico en forma de ave, perteneciente a una forma tipo cerno o guttus, planteamos esa posibilidad para el resto de los ejemplares. Todos poseen secciones idénticas, como podemos observar, y similar decoración pintada, en lo que vendría a ser la cola, con motivos monócromos de estilo geométrico: en la mayor parte de los casos, filetes horizontales de los que penden tracitos verticales o filete del que parten bandas seriadas de semicírculos concéntricos con punto central (fig. 11, 5). Tan sólo en dos casos poseemos referencias de localización precisas: el enterramiento B-14 (sector A; fig. 11, 2) ya comentado por la existencia de una imitación de una copa-escifo y el C-12 (sin documentación gráfica), que concentra diversas piezas de imitación (v. supra). El resto de piezas o no poseen referencia alguna o ésta es muy vaga.

Por otra parte, este tipo de imitación, correspondiente a vasos en forma de ave o paloma posee una 


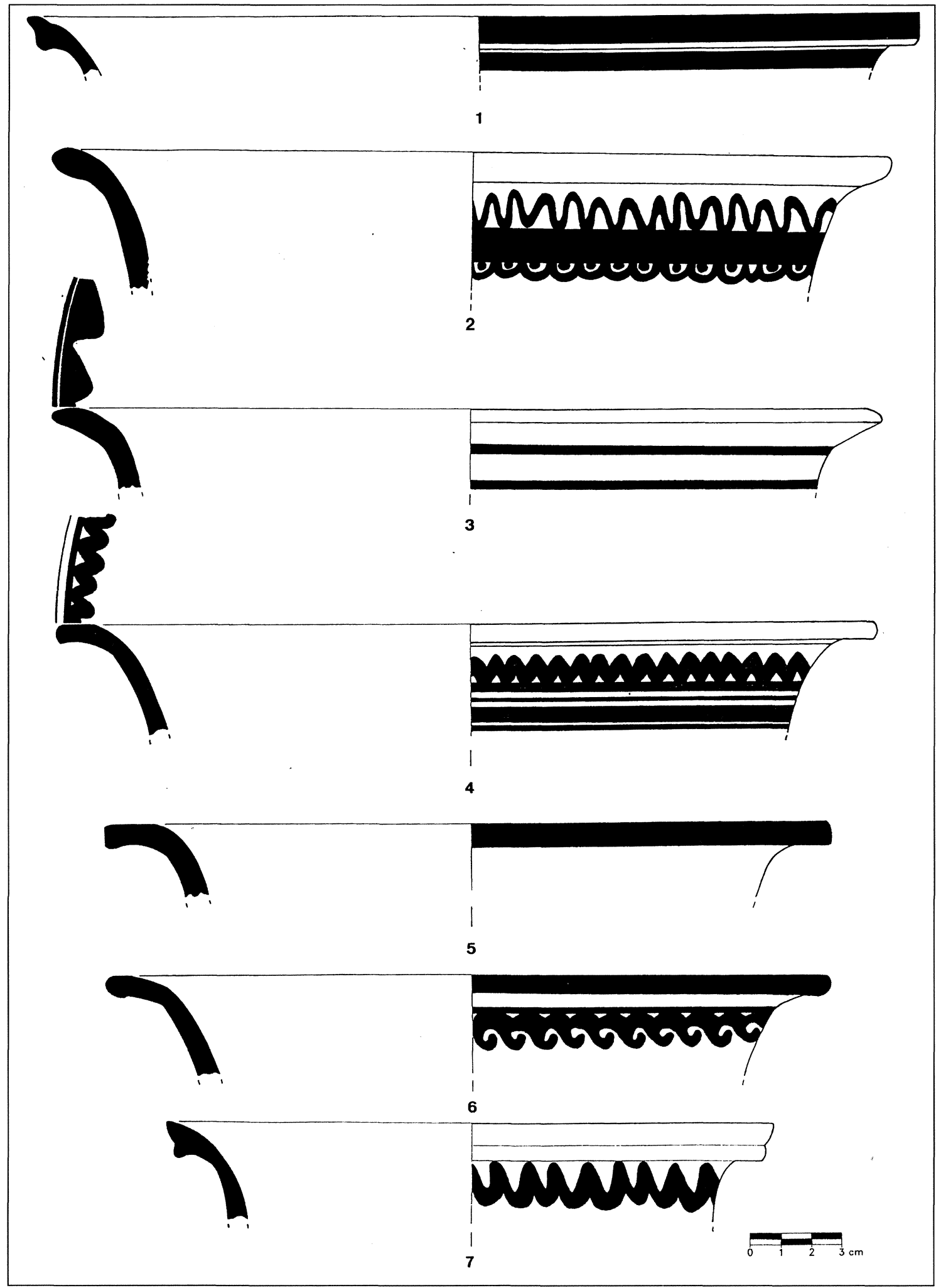

Figura 9.-Posibles vasos crateriformes con decoración pintada geométrica. 


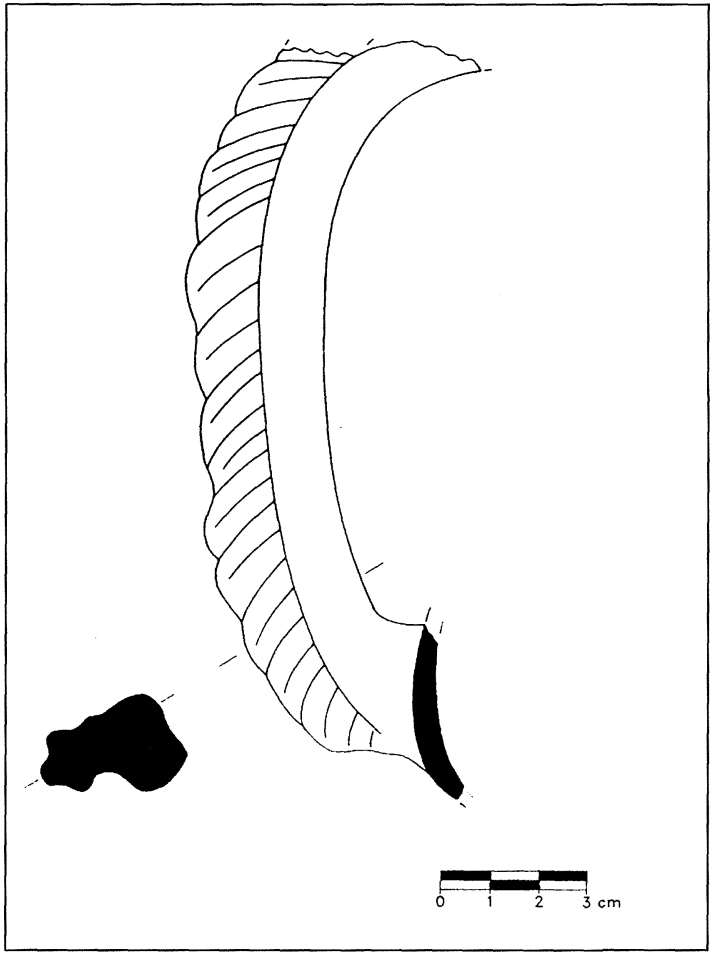

Figura 10.-Asa ibérica de posible vaso crateriforme.

amplia dispersión en el mundo ibérico ${ }^{17}$. La aparición de estos vasos en forma de ave nos pone en contacto con el mundo de la religiosidad mediterránea, especialmente púnica, así como con el universo femenino, asociación que se documenta en la plástica ibérica ${ }^{18}$.

Para concluir este catálogo de piezas que hemos seleccionado, ha de citarse el hallazgo de un pequeño pomo (fig. 11, 1) con decoración pintada de motivos geométricos - líneas onduladas enmarcadas entre filetes-, de tapadera de un recipiente de com-

${ }^{17}$ Efectivamente, desde Andalucía -Cádiz-, pasando por la Meseta - Las Cogotas - hasta Cataluña - Margalef-, destacándose el ejemplo hallado en el poblado de El Amarejo (Broncano y Blánquez, 1985, 252, fig. 141, lám. XXVII.7), cuyo ejemplar se decora con pintura, incisión y estampillado, datándose en los últimos años del s. III a.C. También esta forma ha sido documentada en el yacimiento de Coimbra del Barranco Ancho (Page, 1984, 133, fig. 19.4), El Cigarralejo (Cuadrado, 1987), el depósito votivo del propio Amarejo (Broncano, 1989, 144, fig. 85, lám. LXXXVII) o La Serreta de Alcoy. Pequeños fragmentos, de las características y dimensiones de Corral de Saus, se han hallado en yacimientos del horizonte pleno edetano como Puntal del Llops (Bonet y Mata, 1981, fig. 49).

${ }_{18}$ Véase el conocido ejemplo de la escultura funeraria de la Dama de Baza (Presedo Velo, 1982) u otras representaciones femeninas del mundo ibérico (Blázquez, 1983, 106) que se han interpretado como ofrendas simbólico-religiosas (Idem, 102, 105, 112, 207...). pleja adscripción (v. tabla 1). Podría tratarse de algún tipo de imitación de cajita, lecáne o el llamado «biberón» del que tenemos ejemplares completos en yacimientos como el depósito votivo de El Amarejo, donde se han documentado dos perfiles completos (Broncano, 1989, 122, fig. 92, lám. LXXXVIII y 183, fig. 134, lám. CIII). La pieza plantea muchas incógnitas y la referencia, poco concreta, de su contexto espacial (cuadrículas Ho15-Ho20, sector C) apenas amplía nuestros datos.

\section{EL FENÓMENO DE LAS IMITACIONES EN CORRAL DE SAUS}

La historia de la investigación sobre las imitaciones en la cerámica ibérica es relativamente reciente (Page, 1984, 41; Olmos, 1990). La complejidad y amplitud del fenómeno, unido a su conexión con cuestiones derivadas del concepto de aculturación, ha favorecido la publicación de trabajos de enfoque fundamentalmente empírico a partir de la observación y el estudio de conjuntos en yacimientos concretos (Pereira, 1979; Aranegui y Pla, 1981) ibero reproduce más o menos fielmente. La investigación tiende hoy a observar el tema de las imitaciones de un modo dialéctico, incidiendo en la propia dinámica y originalidad ibérica. En esta línea, podríamos hablar de estímulos, ecos, reminiscencias, residuos, similitudes, concurrencias o influjos y con estos términos no agotaríamos la dificultad del problema. Desde nuestro punto de vista, consideramos la imitación cerámica como un proceso plurivalente y complejo en el sentido que ha propuesto Olmos (en Page, 1984, 271-281). Tal vez esta complejidad ha influido en el hecho de que los principales estudios sobre el tema hayan incidido en aspectos tipológicos y clasificatorios (Olmos, 1990, 41). En esta línea, si bien los modelos formales pueden ser acotados y definidos en gran parte de los casos, mucho más difícil resulta abordar el análisis desde el punto de vista de la iconografía. Generalmente se ha analizado por separado imitación formal, técnica o iconográfica. En nuestra opinión, deben considerarse en su globalidad. Así, podríamos señalar algunos de los ejemplos más destacados de Mogente que hemos presentado, como el plato de peces (fig. 5,1 ) o la cratera con decoración vegetal polícroma (fig. 7), donde aparecen conjuntamente ecos de la forma, la decoración y la técnica de vasos importados.

$\mathrm{El}$ «vaso del héroe y la esfinge», procedente del Corral de Saus (fig. 12), que ha sido presentado en otro trabajo (Izquierdo, 1995b), puede ser conside- 


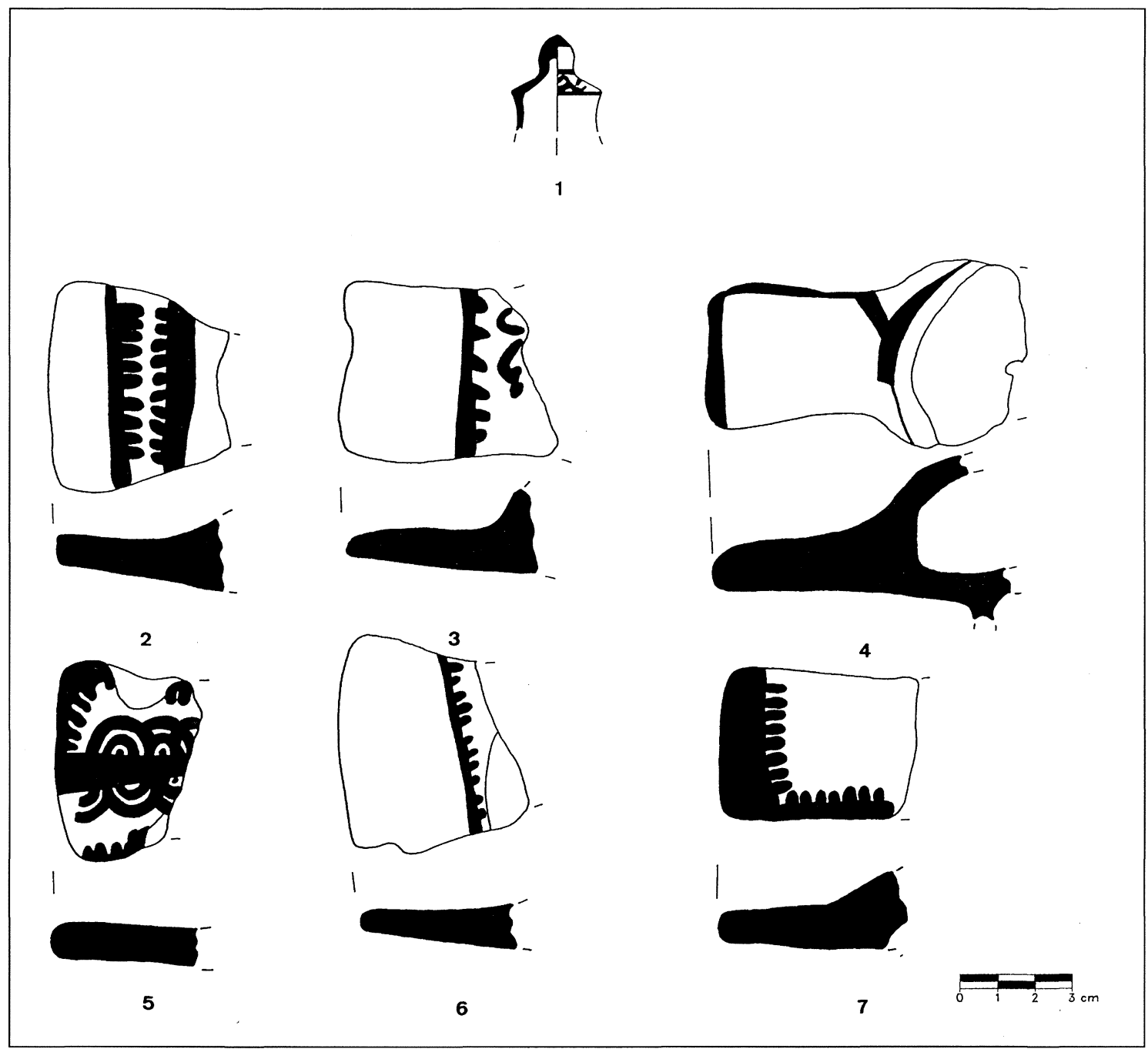

Figura 11.-1 a 7, pequeño pomo de cajita y fragmentos de vasos plásticos con decoración pintada geométrica.

rado otro ejemplo ilustrativo de la problemática que plantea la iconografía (fig. 13). Su tema decorativo principal muestra dos escenas contiguas donde se desarrolla un doble certamen individual entre un personaje masculino con atributos de guerrero, solo, a pie, enfrentado a un ser fantástico de grandes dimensiones, alado y terrorífico (fig. 14). Centrándonos en su iconografía, en general, el tema del enfrentamiento entre el héroe y el monstruo se considera un fenómeno cultural prácticamente universal del que poseemos numerosos ejemplos en ciclos mitológicos orientales como el relato sumerio de Gilgamesh. A su vez, las leyendas heroicas gozan de gran importancia dentro del mito griego, entre las que destacamos la del héroe por excelencia de la mitología clásica, Heracles, contra el león de
Nemea, la hidra de Lerna o el can Cerbero, Perseo y Medusa, Teseo y el Minotauro o Edipo y la Esfinge. Algunas representaciones -fundamentalmente vasculares y sobre gemas - del pasaje de la muerte de la esfinge, aludiendo a esta última leyenda de Edipo, ofrecen paralelos evidentes con las imágenes del vaso de la necrópolis contestana que estudiamos ${ }^{19}$.

Así pues, el interrogante que podríamos plantear en esta ocasión es: ¿se trata de algún modo de imitación de las imágenes que ilustran este mito griego trasvasadas a la cultura ibérica a través de este

\footnotetext{
${ }^{19}$ En este sentido, las referencias bibliográficas al respecto aparecen recogidas en nuestro reciente trabajo sobre el citado vaso (Izquierdo, 1995b).
} 
ejemplo? Consideramos que la respuesta, planteada así la cuestión, es, en nuestro caso, negativa y que el fenómeno es mucho más complejo, sutil e indefinido que la mera recepción e imitación o reproducción de una imagen foránea. Si bien, como hemos planteado, es posible que la sociedad ibérica de época avanzada, entre otros ámbitos geográficos, conociera a través de contactos comerciales y/o culturales de ambiente helenístico, o por transmisión oral, leyendas o imágenes míticas del Mediterráneo antiguo, y entre éstas la conocida y difundida narración legendaria de Edipo y la esfinge, consideramos que la lectura e interpretación de la iconografía de este vaso ha de efectuarse en clave interna ibérica, bajo la óptica de representaciones igualmente ibéri- cas ${ }^{20}$. Nuestra valoración de la leyenda griega cobra sentido, pues, como modelo de otro tiempo, en otro contexto cultural y geográfico; un referente iconográfico, por tanto, que ofrece paralelos con la representación figurada del vaso que hemos comentado y adopta en este excepcional ejemplo rasgos de evidente iberismo. Trascendiendo este ejemplo, la necrópolis del Corral de Saus se configura como un espacio heredero en cierta medida del paisaje monumental atribuido a una fase anterior, donde las ex-

${ }^{20}$ Tal y como ya hemos señalado, véase el caso de las imágenes que decoran los dos vasos de Caudete de las Fuentes (Pla, 1980, figs. 70 y 71) y algunos de La Alcudia de Elche (Ramos Fernández, 1987), que en ocasiones han sido vinculadas a narraciones míticas.

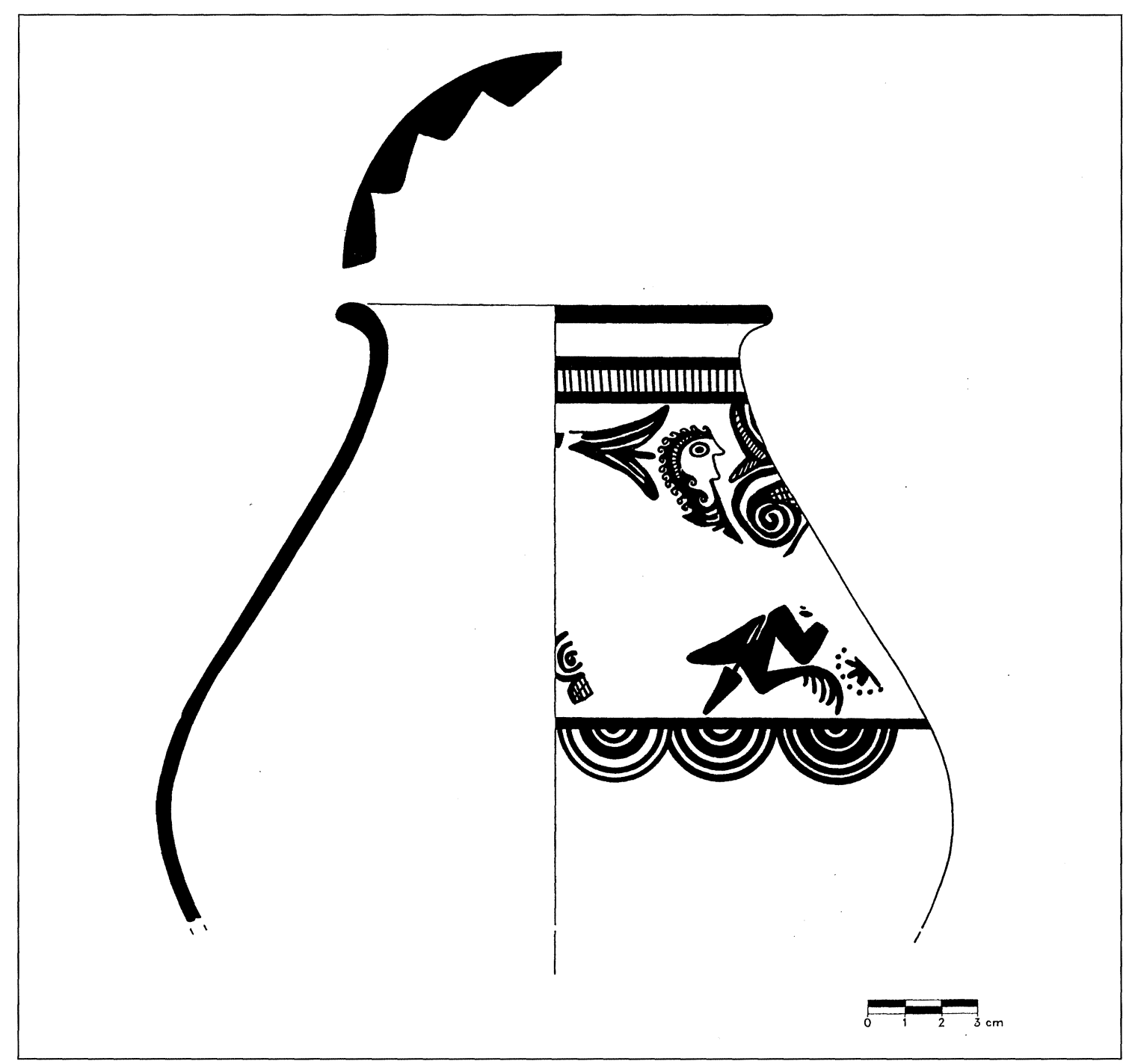

Figura 12.-Perfil del «Vaso del héroe y la esfinge» (Izquierdo, 1995b). 


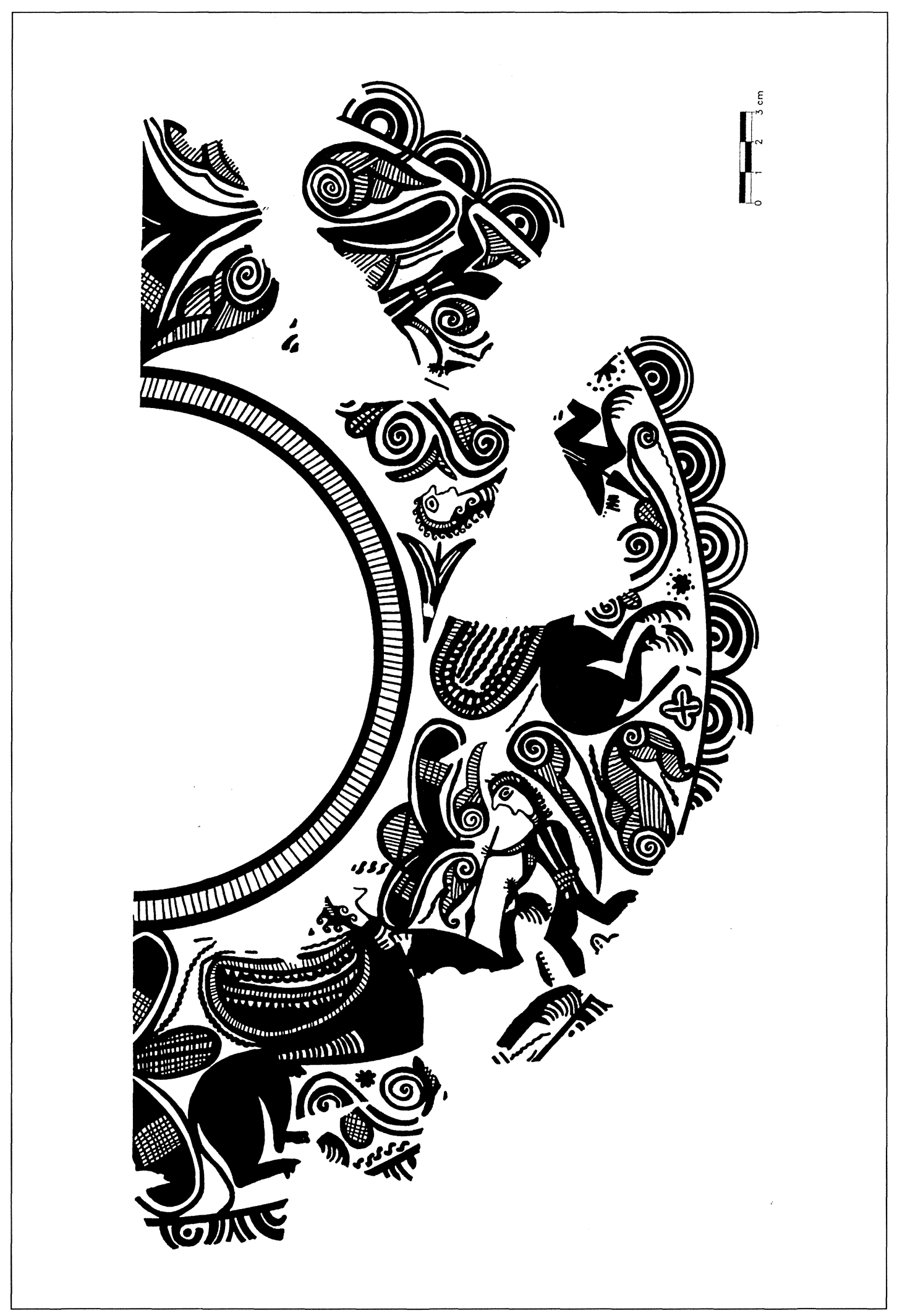




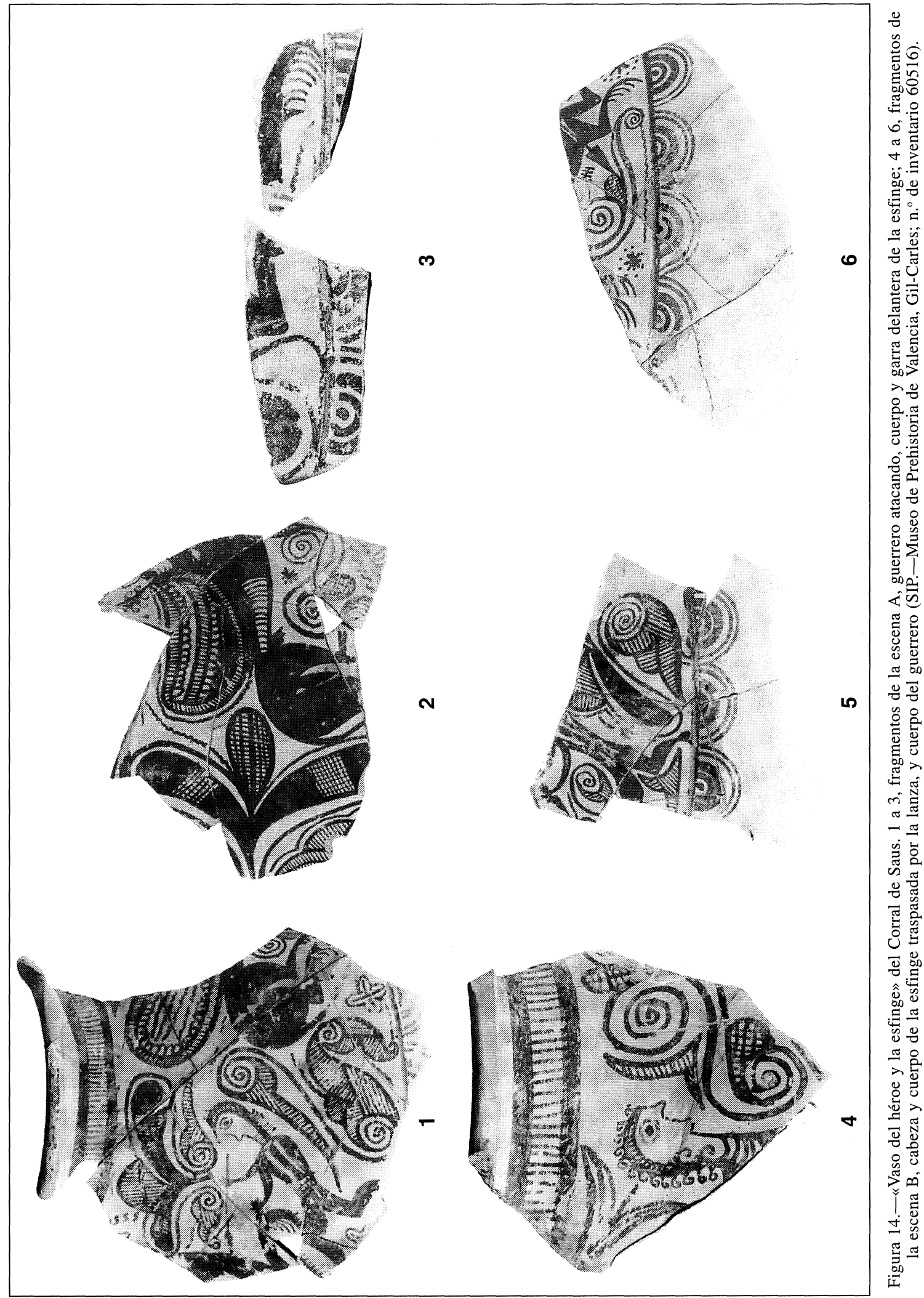


presiones arquitectónicas y escultóricas son exponentes y símbolos de poder. El registro material y más concretamente cerámico cuenta con magníficos ejemplos como el mencionado más arriba, entre otros (Izquierdo, 1995a), que podrían evocar ese modelo de prestigio anterior como una forma de recuperar la memoria o el pasado. Esta idea de evocación de un tiempo anterior podría despejar además algunas incógnitas sobre la cuestión de la cronología de estos vasos.

De cara a la cuestión que aquí nos ocupa, la presencia en las tumbas de piezas que reproducen formas cerámicas mediterráneas confirma el interés de este recinto funerario. Contamos en síntesis con una serie de piezas que conforman un pequeño grupo de variadas formas y decoraciones, localizadas - en diversos ejemplos- en algunos de los enterramientos mejor documentados del yacimiento. Al respecto, si bien la investigación ha considerado en general formas concretas de imitación de manera individual, el Corral de Saus invita a examinar la imitación de conjuntos, de ambientes. Particularmente interesante es el hallazgo del enterramiento $\mathrm{C}-12$, que asocia piezas de hipotéticos orígenes diversos, cuatro elementos singulares que responden a estímulos mediterráneos. En este sentido, a propósito de la clasificación de los productos importados, se ha considerado generalmente de manera aislada las imitaciones griegas, itálicas o, en algún caso, púnicas. Este yacimiento nos hace ver la integración de elementos formales de raíz griega o suritálica junto con otros estímulos más propios del mundo púnico. Vemos que hay un fondo común mediterráneo, un mundo de interrelaciones del que participa lo ibérico.

Otra cuestión será explicar el porqué de estas singularidades. Así, estos vasos, que poseen un carácter extraordinario, se presentan en un contexto específico y singular: las tumbas de una necrópolis. Diversas cerámicas de rasgos excepcionales - tipológicos, decorativos o técnicos- han sido asociadas a contextos sagrados como la pieza de Santa Catalina del Monte en Verdolay o el conjunto de vasos figurados de Liria. Como ya apuntábamos antes, por lo menos para los vasos con decoración vegetal o figurada, posiblemente se trate de vasos de encargo especiales o de lujo, con un uso no doméstico, sino selectivo, adaptado a una funcionalidad y un contexto concreto.

De una manera sintética, nos encontramos en esta necrópolis con una serie de formas relacionadas en gran parte con el servicio de mesa - copas, platos y crateras - cuya deposición como ofrendas en los ajuares de la necrópolis les otorga una dimensión simbólica. Así, no podemos olvidar que en algunos casos - dos de las imitaciones de copas con asas (v. tabla 1) - se evidencian huellas de contacto con el fuego en las superficies del vaso, en posible relación con algún tipo de ritual llevado a cabo en la necrópolis. Las imitaciones de copas con asas, platos -en especial, el magnífico plato de peces-y las piezas fragmentadas - posible imitación de crateras - nos remiten a modelos de la vajilla griega y suritálica. Al respecto, se han documentado escasos testimonios de algunos de estos vasos áticos en el yacimiento pequeños fragmentos de borde, galbo y pie de tres crateras de campana de figuras rojas, datadas en la primera mitad del s. IV a.C. (Izquierdo, 1995a, t. II, fig. 71, 4, fig. 73, 1 y fig. 74, 1) - de modo que nos inclinamos a sugerir que esta tipología no responde a su directa imitación, sino más bien a una corriente sincrónica del gusto de signo helenístico. Los pequeños fragmentos de posibles vasos plásticos, por su parte, nos remiten al mundo del barniz negro y de la coroplastia punicizante, así como los platos, imitación de F. 36 Lamb., evidencian modelos campanienses, presentes y bien documentados en la propia necrópolis (v. supra).

En cuanto a las decoraciones, distintos son los estilos plasmados, mostrando los clásicos motivos geométricos —en las copas y platos-, los temas vegetales - de manera singular en la imitación de cratera con decoración polícroma-, incluso las bandas figuradas —en el plato de peces y el vaso cerrado con jabalí y aves. En todo caso, como hemos observado, la mayor parte de las piezas manifiestan un gusto por la ornamentación evidente. Los temas geométricos ordenan y definen la estructura de los vasos, siendo el tema principal de su decoración, o bien rellenando y compartimentando las escenas figuradas en barrocas composiciones. Del mismo modo, flores y hojas acompañan a las figuraciones animales o por el contrario son protagonistas en la decoración.

Por último, el contexto espacial y la posición estratigráfica de estas piezas plantea algunas dificultades. En primer lugar, no todas poseen una referencia siquiera espacial en el yacimiento. En ocasiones, su localización hace alusión a diversas cuadrículas, por lo que carecemos de precisión y seguridad a la hora de adscribir los vasos a un enterramiento concreto. Por otra parte, las piezas que se asocian a ajuares funerarios bien documentados son escasas, entre ellos, los citados conjuntos B13-14 y C-12, ambos en el sector A, datados en torno a la primera mitad del s. III a.C. sobre la base de la aparición de cerámicas importadas de barniz negro de estas cronologías e ibéricas con decoración pintada de estilo geométrico 
TABLA 1

\begin{tabular}{|c|c|c|c|c|c|c|c|c|c|c|c|c|c|}
\hline \multirow{3}{*}{ N. ${ }^{\circ}$} & \multirow{2}{*}{\multicolumn{5}{|c|}{ LOCALIZACIÓN }} & \multirow{3}{*}{$\begin{array}{c}\text { INVENT. } \\
\text { S.I.P. }\end{array}$} & \multirow[t]{3}{*}{ PI. F } & \multirow[t]{3}{*}{ FRS. } & \multirow[t]{3}{*}{ CLASE } & \multirow[t]{3}{*}{ TIPO' $^{\prime}$} & \multicolumn{3}{|c|}{ FORMA } \\
\hline & & & & & & & & & & & \multirow{2}{*}{$\begin{array}{l}\text { LABIO/ } \\
\text { BORDE }\end{array}$} & \multirow{2}{*}{$\begin{array}{l}\text { BASE/ } \\
\text { POMO }\end{array}$} & \multirow{2}{*}{$\begin{array}{c}\text { PREN } \\
\text { POS/SEC }\end{array}$} \\
\hline & SECTOR & CUAD. & CAPA & CAM. & OTRA & & & & & & & & \\
\hline 1 & $\mathrm{~A}$ & B13-B14 & 3 & 76 & INCIN & 59991 & $\mathrm{~s}$ & & A.O & VI.2 & $s$ & $\mathrm{AN}^{-}$ & $\mathrm{H} / \mathrm{C}$ \\
\hline 2 & SUP & & & 74 & INCIN N. ${ }^{\circ}$ & 60657 & $\mathrm{~S}$ & & A.O & VI.2 & $\mathrm{s}$ & $\mathrm{AN}$ & $\mathrm{H} / \mathrm{C}$ \\
\hline 3 & $\mathrm{~A}$ & $\mathrm{Cl2}$ & 1 & 72 & & 59938 & $\mathrm{~S}$ & & A.O & VI. 2 & $\mathrm{~s}$ & $\mathrm{AN}$ & $\mathrm{H} / \mathrm{C}$ \\
\hline 4 & A & $\mathrm{C} 12$ & 1 & 72 & & 62258 & $\mathrm{~s}$ & & A.O & VI. 6 & $\mathrm{PE}$ & ¿AL? & \\
\hline 5 & $\mathrm{C}$ & B0-H011 & 1 & 73 & & 59973 & s & & A.O & VI.6 & $\mathrm{PE}$ & $\mathrm{AL}$ & \\
\hline 6 & A & E14 & 2 & 72 & & 62131 & $\mathrm{~S}$ & & A.O & VI. 6 & $\mathrm{PE}$ & $\mathrm{AN}$ & \\
\hline 7 & $\mathrm{~A}$ & A12 & 1 & 72 & & 60029 & $\mathrm{~N}$ & \begin{tabular}{|l}
1 \\
\end{tabular} & A.O & VI.6 & $\mathrm{PE}$ & & \\
\hline 8 & $\mathrm{C}$ & BO12-14 & & 73 & TALUD-TEST & 60035 & $\mathrm{~N}$ & 1 & A.O & VI. 6 & $\mathrm{PE}$ & & \\
\hline 9 & $\mathrm{C}$ & DO-EO11 & 3 & 73 & & 60193 & $\mathrm{~N}$ & 1 & A.O & VI.5 & $\mathrm{s}$ & & \\
\hline 10 & A & G-J 16 & 2 & 72 & & 62175 & $\mathrm{~N}$ & \begin{tabular}{|l|}
1 \\
\end{tabular} & A.O & ¿VI.5? & $\mathrm{s}$ & & \\
\hline 11 & $\mathrm{~A}$ & $\mathrm{C} 12$ & 3 & 76 & INCIN & 62065 & $\mathrm{~N}$ & \begin{tabular}{|l|}
1 \\
\end{tabular} & $\mathrm{~A}-\mathrm{O}$ & ¿VI.5? & $\mathrm{s}$ & & \\
\hline 12 & SR & & & & & 60654 & $\mathrm{~N}$ & I & A.O & IND. & & $\mathrm{CO}$ & \\
\hline 13 & $\mathrm{~A}$ & F11 & & 72 & & 60769 & $\mathrm{~N}$ & \begin{tabular}{|l|}
1 \\
\end{tabular} & A.O & ¿VI.5? & & & $\mathrm{H} / \mathrm{T}$ \\
\hline 14 & A & & & 72 & ENC. TUMBA & 59799 & $\mathrm{~N}$ & \begin{tabular}{|l|}
2 \\
\end{tabular} & A.O & ¿VI.5? & MO & & \\
\hline 15 & A & $\mathrm{A} 13$ & 1 & 72 & & 62338 & $\mathrm{~N}$ & \begin{tabular}{|c|}
1 \\
\end{tabular} & A.O & ¿VI.5? & $\mathrm{S}$ & & \\
\hline 16 & $\mathrm{~A}$ & A-K 19 & 1 & 75 & & 60081 & $\mathrm{~N}$ & 1 & A.O & ¿VI.5? & $\mathrm{s}$ & & \\
\hline 17 & $\mathrm{~A}$ & A-K 19 & 1 & 75 & & 60081 & \begin{tabular}{l|l}
$\mathrm{N}$ \\
\end{tabular} & \begin{tabular}{|l|}
1 \\
\end{tabular} & A.O & ¿VII.S? & $\mathrm{s}$ & & \\
\hline 18 & $\mathrm{C}$ & HO12-21 & 1 & 72 & & 60063 & $\mathrm{~N}$ & \begin{tabular}{|l|l}
1 \\
\end{tabular} & A.O & ¿VI.5? & $\mathrm{s}$ & & \\
\hline 19 & A & A-K 19 & 1 & 75 & & 60081 & $\mathrm{~N}$ & 2 & A.O & ¿VI.5? & S & & \\
\hline 20 & $\mathrm{C}$ & BO12-14 & & 73 & TALUD TEST & 60035 & $\mathrm{~N}$ & 1 & A.O & ¿VI.5? & MO & & \\
\hline 21 & A & A11-16 & 1 & 73 & & 62159 & $\mathrm{~N}$ & 1 & A.O & ¿VI.5? & & & $\mathrm{V} / \mathrm{C}$ \\
\hline 22 & $\mathrm{C}$ & HO 15-20 & 1 & 76 & & 60488 & $\mathrm{~N}$ & 1 & A.O & VI. 8 & & & \\
\hline 23 & $\mathrm{~A}$ & B14 & 1 & 72 & & 60985 & $\mathrm{~N}$ & 1 & A.O & VI.7 & & & \\
\hline 24 & SR & & & & & 62616 & $\mathrm{~N}$ & 1 & A.O & VI.7 & & & \\
\hline 25 & $\mathrm{~B}$ & L-N 13 & 1 & 73 & & 62498 & $\mathrm{~N}$ & 1 & A.O & VI.7 & & & \\
\hline 26 & $S R$ & & & & & 62565 & $\mathrm{~N}$ & 1 & A.O & VI.7 & & & \\
\hline 27 & $\mathrm{C}$ & DO-EO $18-21$ & & 74 & & 62488 & $\mathrm{~N}$ & 1 & A.O & VI.7 & & & \\
\hline 28 & SR & & & & & 62405 & $\mathrm{~N}$ & 1 & A.O & VI.7 & & & \\
\hline 29 & $\bar{A}$ & $\mathrm{C} 12$ & 1 & 76 & INCIN & 62410 & $\mathrm{~N}$ & 1 & A.O & VI.7 & & & \\
\hline 30 & $\mathrm{~A}$ & A-C $11-13$ & 1 & 72 & & 60516 & $\mathrm{~S}$ & 40 & A.O & II. 2.2 .1 & $\mathrm{~S}$ & $i ?$ & \\
\hline
\end{tabular}

TABLA 2

\begin{tabular}{|c|c|c|c|c|c|c|c|c|c|c|c|c|c|c|c|}
\hline \multirow[t]{3}{*}{ N. ${ }^{\circ}$} & \multicolumn{3}{|c|}{ DIMENSIONES $(\mathrm{cm})}$. & \multirow{2}{*}{\multicolumn{4}{|c|}{$\frac{\text { PASTA }}{\text { CARACT, DESGRAS. }}$}} & \multicolumn{4}{|c|}{ SUPERFICIES } & \multicolumn{3}{|c|}{ DECORACIÓN } & \multirow[t]{3}{*}{ FIGURAS } \\
\hline & \multirow{2}{*}{$\begin{array}{c}\varnothing \\
\text { BOCA }\end{array}$} & \multirow{2}{*}{$\begin{array}{c}\varnothing \mathrm{BASE} / \\
\text { POMO }\end{array}$} & \multirow[b]{2}{*}{ ALT. } & & & & & \multicolumn{2}{|c|}{ INT. } & \multicolumn{2}{|c|}{ EXT. } & \multirow{2}{*}{$\begin{array}{l}\text { INT. } \\
\text { TIPO }\end{array}$} & \multirow{2}{*}{$\begin{array}{l}\text { EXT. } \\
\text { TIPO }\end{array}$} & \multirow{2}{*}{$\frac{\text { LABIO }}{\text { TIPO }}$} & \\
\hline & & & & COL. & cocc. & PRES. & COL. & COL. & TRAT. & COL. & TRAT. & & & & \\
\hline 1 & 11 & 6 & & $\mathrm{MC}$ & H & $\mathrm{N}$ & & $\mathrm{MC}$ & $\mathrm{AL}$ & MC & $\mathrm{AL}$ & & PG & PG & - \\
\hline 2 & 11 & 5 & 7.1 & AN & $\mathrm{H}$ & $\mathrm{E}$ & B & MC & $\mathrm{AL}$ & AN & $\mathrm{AL}$ & PG & PG & & fig. $3,1 \mathrm{Q}$ \\
\hline 3 & 11 & 5 & 6.1 & MO & $\mathrm{H}$ & $\mathrm{N}$ & & MC & $\mathrm{AL}$ & AN & $\mathrm{AL}$ & & PG & PG & fig. $3,2 \mathrm{Q}$ \\
\hline 4 & 26 & 3 & 4.9 & AN-GC & A & E & B & AN & $\overline{\mathrm{AL}}$ & AN & $\mathrm{AL}$ & PS & PG & PG & fig. 4 \\
\hline 5 & 20 & 6,8 & 4,5 & NA & $\mathrm{H}$ & $\mathrm{N}$ & & NA & $\overline{\mathrm{AL}}$ & NA & $\mathrm{AL}$ & PG & PG & PG & fig. 5,1 \\
\hline 6 & 20 & 8,4 & 4 & GO & $\mathrm{H}$ & $\mathrm{E}$ & B & $\mathrm{GO}$ & $\mathrm{AL}$ & GO & $\mathrm{AL}$ & PG & PG & PG & fig. 5,2 \\
\hline 7 & 24 & & 3 & & & & & & & & & & & & fig. 5,3 \\
\hline 8 & 28 & & 3,5 & & & & & & & & & & & & fig. 5,4 \\
\hline 9 & 32 & & 11 & & & & & & & & & PG & PG & PG & fig. 6 \\
\hline 10 & 26 & & 7 & & & & & AN & $\overline{A L}$ & AN & $\mathrm{AL}$ & & PB & & fig. 7,1 \\
\hline 11 & 26 & & 3 & & & & & AN & $\mathrm{AL}$ & AN & $\mathrm{AL}$ & & PB & PG & fig. 7,2 \\
\hline 12 & & 7 & 13 & & & & & & & & & & PB & & fig. 7,3 \\
\hline 13 & & & 14,7 & GC-AN & $\mathrm{A}$ & $\mathrm{E}$ & B & AN & $\mathrm{AL}$ & AN & $\mathrm{AL}$ & & $\mathrm{PF}$ & & fig. 8,1 y 2 \\
\hline 14 & 32 & & & & & & & & & & & & PG & PG & fig. 9,1 \\
\hline 15 & 30 & & 5 & & & & & & & & & & PG & & fig. 9,2 \\
\hline 16 & 28 & & 2,9 & & & & & & & & & & PG & PG & fig. 9,3 \\
\hline 17 & 27,3 & & 3,5 & & & & & & & & & & PG & PG & fig. 9,4 \\
\hline 18 & 24 & & 2,3 & & & & & & & & & & & PG & fig. 9,5 \\
\hline 19 & 23,5 & & 3,4 & & & & & & & & & & PG & PG & fig. 9,6 \\
\hline 20 & 20 & & 3,3 & & & & & & & & & & PG & & fig. 9,7 \\
\hline 21 & & & 17 & & & & & AN & $\overline{\mathrm{AL}}$ & AN & $\mathrm{AL}$ & & PG & & fig. 10 \\
\hline 22 & 2 & & 2,5 & & & & & & & & & & PG & & fig. 11,1 \\
\hline 23 & 4,3 & 4,5 & 1,8 & GC-AN & $\mathrm{A}$ & $\mathrm{E}$ & $\mathrm{E}$ & AN & $\mathrm{AL}$ & AN & $\mathrm{AL}$ & & PG & & fig. 11,2 \\
\hline 24 & 5 & 4,5 & 2 & & & & & AN & $\overline{A L}$ & AN & $\mathrm{AL}$ & & PG & & fig. 11,3 \\
\hline 25 & 8,4 & 3,8 & 4,2 & GC-AN & $\mathrm{A}$ & $E$ & B & AN & $\overline{A L}$ & AN & $\mathrm{AL}$ & & & & fig. 11,4 \\
\hline 26 & 3,5 & 5,5 & 1 & & & & & $\mathrm{AN}$ & $\mathrm{AL}$ & AN & $\mathrm{AL}$ & & PG & & fig. 11,5 \\
\hline 27 & 4,7 & 5,7 & 1,1 & GC-AN & $\mathrm{A}$ & $\mathrm{E}$ & $E$ & MC & $\overline{\mathrm{AL}}$ & MC & $\mathrm{AL}$ & & PG & & fig. 11,6 \\
\hline 28 & 5 & 4 & 2 & & & & & AN & $\mathrm{AL}$ & AN & $\mathrm{AL}$ & & PG & & fig. 11,7 \\
\hline 29 & 8,4 & 4,9 & 2 & GC-AN & A & $\mathrm{E}$ & $\mathrm{E}$ & AN & $\mathrm{AL}$ & $\mathrm{AN}$ & $\mathrm{AL}$ & & PG & & - \\
\hline 30 & 13 & i? & 18 & GC-AN & $\mathrm{H}$ & $\mathrm{E}$ & B & AN & $\overline{A L}$ & AN & $\mathrm{AL}$ & & $\mathrm{PF}$ & PG & fig. 12,13 y 14 \\
\hline
\end{tabular}

\footnotetext{
1 Terminología de Mata y Bonet (1992).
} 
(v. supra). A pesar de estos vacíos de información, la distribución de las piezas y fragmentos de imitación con una referencia precisa (fig. 2) nos lleva al entorno de las dos grandes tumbas y más concretamente al área entre ambas estructuras, donde aparecen concentrados estos vasos. Se trata de un espacio nuclear, el más destacado de la necrópolis, tanto desde el punto de vista de las estructuras y la monumentalidad como por los materiales hallados, procedentes de los ajuares funerarios depositados en las tumbas. Igualmente, el hallazgo del llamado vaso «del héroe y la esfinge», cuyos fragmentos aparecieron dispersos en diversas cuadrículas de este espacio concreto (Izquierdo, 1995b, fig. 2), así como la distribución de las producciones importadas de cerámica ática, barniz negro del s. III a.C., campaniense, incluso la escasa cerámica romana existente, concentrada en el área de los dos empedrados y su entorno más próximo (Izquierdo, 1995a, t. II, figs. 103 y 104), confirman la importancia de este espacio, que se reafirma con el hallazgo de las piezas de imitación presentadas en este trabajo.

\section{BIBLIOGRAFÍA}

AbAD, L. y SANZ, R. (1995): «La cerámica ibérica con decoración figurada de la provincia de Albacete. Iconografía y territorialidad», SaguntumP.L.A.V., 29, Homenatge a la Pra. Dra. Milagros Gil-Mascarell Boscá, I, 73-84.

Almagro Gorbea, M. (1987): «El pilar-estela de las «Damitas de Mogente» (Corral de Saus, Mogente, Valencia)». Archivo de Prehistoria Levantina, XVII, 199-228.

ApARICIO, J. (1976): «Necrópolis ibérica del Corral de Saus, Mogente (Valencia)». Mogente. Programa Oficial de Fiestas.

Aparicio, J. (1982): «La necrópolis de Corral de Saus y las evidencias de una primera revolución social». Papers de la Costera, 2, 42-45.

ApARICIO, J. (1984): «Tres monumentos ibéricos valencianos: La Bastida, Meca y el Corral de Saus». Varia III. La Cultura Ibérica, 145-205. Homenaje a Domingo Fletcher Valls. Valencia.

Aranegui Gascó, C. (1970): «Cerámica ibérica de La Serreta». P.L.A.V.-Saguntum, 10, 107-122.

Aranegui Gascó, C. (1974): «Consideraciones sobre la cerámica con decoración pintada polícroma en el País Valenciano». Miscelánea Arqueológica, I, XXV Aniversario de los cursos de Ampurias, 1947-1971, 87-99. Barcelona.

Aranegui Gascó, C. (1975): «Las artes decorativas en la cerámica ibérica valenciana». Actas del
XXIII Congreso Internacional de Historia del Arte. (Granada 1973) Vol. I, 45-64.

Aranegui Gascó, C. (1992): «Una falcata decorada con inscripción ibérica. Juegos gladatorios y venatorios. Estudios de Arqueología ibérica y romana». Homenaje a Enrique Pla Ballester. Trabajos Varios del Servei d'Investigació Prehistòrica, 89, 319-329.

Aranegui Gascó, C. (e.p.): «Los platos de peces y el más allá». Complutum. Homenaje a Fernández Miranda.

Aranegui, C. y Pla Ballester, E. (1981): «La cerámica ibérica». La Baja época de la Cultura Ibérica. (Madrid, 1979), 73-114. Madrid.

Aranegui, C. y Pérez Ballester, J. (1989): «Imitaciones de formas clásicas en cerámica ibérica; siglos v-III a. C.». XXIX Convegno di Studi Sulla Magna Grecia, (Tarento, 6-11 Octubre).

Aranegui, C.; Jodin, A.; Llobregat, E.; Rouillard, P., y Uuroz, J. (1993): La nécropole ibérique de Cabezo Lucero. Guardamar del Segura. Alicante. Madrid-Alicante.

Aranegui, C.; Mata, C.; Pérez Ballester, J., y MARTí, A. (e.p.): Damas y caballeros en la ciudad ibérica: las cerámicas de Edeta-Llíria (Valencia).

Aranegui, C.; Bonet, H.; Martí, M. A.; Mata, C., y Pérez BAllester, J. (e.p.): «La cerámica con decoración figurada y vegetal del Tossal de Sant Miquel (Llíria, Valencia): una nueva propuesta metodológica». Iconografía ibérica e Iconografía itálica: Propuestas de interpretación y lectura (Roma, 1993).

Ballester, I.; Fletcher, D.; Pla, E., Jorda, F. y AlCÁCER, J. (1954): Corpus Vasorum Hispanorum. Cerámica del Cerro de San Miguel de Liria. Madrid.

BlÁNQuez, J. J. (ed.) (1995): El mundo ibérico: una nueva imagen en los albores del año 2.000. (Catálogo de la exposición). Toledo.

BlÁzqueZ, J. M.a (1983): Religiones prerromanas. Primitivas religiones ibéricas Vol. II, Madrid.

Bonet Rosado, H. (1993): El Tossal de Sant Miquel de Lliria: la antigua Edeta y su territorio. Facultad de Geografía e Historia. Universitat de València. Tesis Doctoral inédita.

Bonet, H. y MATA, C. (1981): «El poblado ibérico del Puntal des Llops (Olocau, Valencia)». Trabajos Varios del Servei d'Investigació Prehistòrica, 71, Valencia.

Bonet, H. y MATA, C. (1988): «Imitaciones de cerámica campaniense en la Edetania y la Contestania». Archivo Español de Arqueología, 61, 5-39.

BroncANo, S. (1989): «El depósito votivo ibérico de 
El Amarejo (Bonete, Albacete)». Excavaciones Arqueológicas en España, 156.

Broncano, S.; BlánqueZ, J. (1985): «El Amarejo (Bonete, Albacete)». Excavaciones Arqueológicas de España, 139.

Cuadrado, E. (1972): «Tipología de la cerámica ibérica fina de El Cigarralejo (Mula, Murcia)». Trabajos de Prehistoria, XXIX, 125-158.

Cuadrado, E. (1987): «La Necrópolis ibérica de El Cigarralejo (Mula, Murcia)». Bibliotheca Praehistorica Hispana, XXIII, Madrid.

FLeTCher VALLS, D. (1954): «La cueva y el poblado de La Torre del Mal Paso (Castellnovo, Castellón)». Archivo de Prehistoria Levantina, V, 187224.

Fletcher Valls, D., y Pla Ballester, E. (1972): «La Necrópolis ibérica de Corral de Saus». Mogente. Programa Oficial de Fiestas.

Fletcher Valls, D. y Pla Ballester, E. (1974): «Las esculturas en piedra de "El Corral de Saus" (Mogente)». Bellas Artes, 74, año V, núm. 36, 38-39.

Fletcher Valls, D. y Pla Ballester, E. (1977): «Restos escultóricos de la necrópolis ibérica de Corral de Saus (Mogente, Valencia)». Revista de la Universidad Complutense, XXVI, núm. 109, Homenaje a García Bellido, Vol. III, 56-62.

Fletcher Valls, D.; Pla Ballester, E. y Alcácer, J. (1969): «La Bastida de les Alcuses (Mogente, Valencia)», Trabajos Varios del Servei d'Investigació Prehistòrica, 25, Valencia.

IzQUiERdo PeraILe, M. ${ }^{\mathrm{a}}$ I. (1995a): El contexto arqueológico de la necrópolis ibérica del Corral de Saus (Moixent, Valencia). Tesis de Licenciatura inédita. Facultat de Geografia i Història. Universitat de València.

Izquierdo Peraile, M. ${ }^{a}$ I. (1995b): «Un vaso inédito con excepcional decoración pintada procedente de la necrópolis ibérica de Corral de Saus (Moixent, Valencia)». Saguntum-P. L. A. V., 29, Homenatge a la Pra. Dra. Milagro Gil-Mascarell Boscá, I, 93-104. Valencia.

IzQuierdo Peraile, M. ${ }^{a}$ I. (e.p.): «El contexto arqueológico de las dos grandes tumbas del del Corral de Saus (Moixent, Valencia)». Verdolay, 7, Homenaje a Ana M. ${ }^{a}$ Muñoz.

Jorge Aragoneses, M. (1969): «El vaso ibérico de Santa Catalina del Monte (Murcia)». Archivo Español de Arqueología, 42, 200-204.

Lillo, P. (1981): El poblamiento ibérico en Murcia. Universidad de Murcia, Academia Alfonso X el Sabio. Murcia.

Lissarrague, F. (1989): «Voyages d' images: iconographie et aires culturalles». Grecs et ibères au IV siècle avant Jésus-Christ. Commerce et ico- nographie. Publications du Centre Pierre Paris (U.A. 991), 19, 261-271. Paris.

Llobregat, E. A. (1972): Contestania ibérica. Instituto de Estudios Alicantinos. Alicante.

MatA, C. (1991): «Los Villares (Caudete de las fuentes, Valencia). Orígenes y evolución de la eultura ibérica». Trabajos Varios del Servei d'Investigació Prehistòrica, $\mathrm{n}^{\circ} 88$, Valencia.

MATA, C. y Bonet, H. (1992): «La cerámica ibérica: ensayo de tipología». Homenaje a Enrique Pla Ballester. Trabajos Varios del S.I.P. $\mathrm{N}^{\circ}$ 89, 117173. Valencia.

McPhee, I. y Trendall, A. D. (1987): Greek red-figured fish-plates, Basel.

Morel, J. P., (1969): «L' atelier des petites estampilles». Mélanges d'Archeologie et d' Histoire, LXXXI, 1, 59-117. Roma.

NoRdstrom, S. (1969-1973): La céramique peinte ibérique de la province de d'Alicante, I y II. Acta Universitatis Stockholmiensis. VI y VIII. Stockholm.

Oliver FoIX, A. (1982-1983): «Nuevas aportaciones para el estudio de la cerámica polícroma ibérica en el País Valenciano». Cuadernos de Prehistoria y Arqueología Castellonense, 9, 193-203.

Olmos, R. (1987): «Posibles vasos de encargo en la Cerámica ibérica del Sureste». Archivo Español de Arqueología, 60, 21-42.

Olmos, R. (1989): «Míticos pobladores del mar: tritones, hipocampos y delfines durante la época prerromana y republicana en España». Lecturas de Historia del Arte, 1, 23-62.

Olmos, R. (1990): «Imitaciones, producción y sociedad: algunas consideraciones en torno a la cerámica ibérica». Verdolay, 2, 39-44.

PAGe Del Pozo, V. (1984): Imitaciones de influjo griego en la cerámica ibérica de Valencia, Alicante y Murcia. Iberia Graeca, Serie Arqueológica, 1, Madrid.

Pereira Sieso, J. (1979): «La cerámica ibérica procedente de Toya (Peal de Becerro, Jaén) en el Museo Arqueológico Nacional». Trabajos de Prehistoria, 36, 289-348.

Pereira Sieso, J. y SÁNCHEZ, C. (1985): «Imitaciones ibéricas de vasos áticos en Andalucía». Ceràmiques gregues $i$ helenístiques à la Peninsula Ibèrica, 87-100.

Pérez Ballester, J. (1987): «El taller de las Pequeñas Estampillas: revisión y precisiones a la luz de las cerámicas de barniz negro de Gabii. Los últimos hallazgos en el Levante y Sureste español». Archivo Español de Arqueología, 60, 43-72.

Pericot, L. (1979): Cerámica Ibérica. Barcelona. Pla, E. (1980): «Los Villares (Caudete de las Fuen- 
tes, Valencia)». Trabajos Varios del Servei d'Investigació Prehistòrica, $\mathrm{n}^{\circ}$ 68. Diputación de Valencia. Apéndice B, 93-108.

Presedo Velo, F. J. (1982): «La necrópolis de Baza». E. A. E., 119, Madrid.

QuEsADA, R. (1990): «Falcatas ibéricas con damasquinados en plata». Verdolay 2, 45-59.

RAGA, M. (1994): Los materiales del poblado ibérico de «La Covalta» (Albaida, Valencia). Facultad de Geografía e Historia. Universitat de València. Memoria de licenciatura, inédita.

Ramos FERnÁndeZ, R. (1987): «Iconografía funera- ria en algunas Cerámicas Ibéricas de La Alcudia». Archivo Español de Arqueología, 60, 231236.

SAnMartí, E. (1973): «El taller de las pequeñas estampillas en la Península Ibérica». Ampurias, 35, 135-174.

SANMARTí, E. (1978): «L'atelier des patères à trois palmettes radiales et quelques productions connexes». Archéologie en Languedoc, 1, 21-36, Sète.

Serra Ráfols, J. C. (1941): «El tesoro de Tivissa». Ampurias, 3, 15-33. 